\title{
Mechanics of right ventricular dysfunction in pulmonary arterial hypertension and heart failure with preserved ejection fraction
}

\author{
Roberto J. Bernardo $^{1,2}$, Francois Haddad ${ }^{2,3,4}$, Etienne J. Couture ${ }^{5,6,7}$, Georg Hansmann ${ }^{8}$, \\ Vinicio A. de Jesus Perez ${ }^{1,2}$, André Y. Denault ${ }^{9,10}$, Frances S. de Man ${ }^{11}$, Myriam Amsallem ${ }^{2,3,4}$ \\ ${ }^{1}$ Division of Pulmonary, Allergy and Critical Care, Stanford University School of Medicine, Stanford, CA, USA; ${ }^{2}$ Vera Moulton Wall Center for \\ Pulmonary Vascular Disease, Stanford, CA, USA; ${ }^{3}$ Division of Cardiovascular Medicine, Stanford University School of Medicine, Stanford, CA, \\ USA; ${ }^{4}$ Stanford Cardiovascular Institute, Stanford, CA, USA; ${ }^{5}$ Department of Anesthesiology, ${ }^{6}$ Intensive Care Medicine Division, Department of \\ Medicine, ${ }^{7}$ Research Center, Quebec Heart and Lung Institute, Quebec, Canada; ${ }^{8}$ Department of Pediatric Cardiology and Critical Care, Hannover \\ Medical School, Hannover, Germany; ${ }^{9}$ Department of Anesthesiology and Division of Critical Care, Montreal Heart Institute, Université de \\ Montréal, Montreal, Canada; ${ }^{10}$ Division of Critical Care, Centre Hospitalier de l'Université de Montréal, Montreal, Canada; ${ }^{11}$ Amsterdam University \\ Medical Center, Vrije Universiteit Amsterdam, Department of Pulmonary Medicine, PHEniX laboratory, Amsterdam Cardiovascular Sciences, \\ Amsterdam, The Netherlands \\ Contributions: (I) Conception and design: RJ Bernardo, F Haddad, M Amsallem; (II) Administrative support: F Haddad; (III) Provision of study \\ materials or patients: All authors; (IV) Collection and assembly of data: All authors; (V) Data analysis and interpretation: All authors; (VI) Manuscript \\ writing: All authors; (VII) Final approval of manuscript: All authors. \\ Correspondence to: Roberto J. Bernardo, MD, MS; Myriam Amsallem, MD, PhD. Department of Medicine, Stanford University School of Medicine, \\ 300 Pasteur Drive, Stanford 94305, CA, USA. Email: rjbern35@stanford.edu; mamsalle@stanford.edu.
}

\begin{abstract}
Right ventricular (RV) dysfunction is the most important determinant of survival in patients with pulmonary hypertension (PH). The manifestations of RV dysfunction not only include changes in global RV systolic function but also abnormalities in the pattern of contraction and synchrony. The effects of $\mathrm{PH}$ on the right ventricle have been mainly studied in patients with pulmonary arterial hypertension (PAH). However, with the demographic shift towards an aging population, heart failure with preserved ejection fraction (HFpEF) has become an important etiology of $\mathrm{PH}$ in recent years. There are significant differences in RV mechanics, function and adaptation between patients with $\mathrm{PAH}$ and $\mathrm{HFpEF}$ (with or without $\mathrm{PH}$ ), which are related to different patterns of remodeling and dysfunction. Due to the unique features of the RV chamber, its connection with the main pulmonary artery and the pulmonary circulation, an understanding of the mechanics of RV function and its clinical significance is mandatory for both entities. In this review, we describe the mechanics of the pressure overloaded right ventricle. We review the different mechanical components of RV dysfunction and ventricular dyssynchrony, followed by insights via analysis of pressurevolume loop, energetics and novel blood flow patterns, such as vortex imaging. We conduct an in-depth comparison of prevalence and characteristics of RV dysfunction in $\mathrm{HFpEF}$ and $\mathrm{PAH}$, and summarize key outcome studies. Finally, we provide a perspective on needed and expected future work in the field of RV mechanics.
\end{abstract}

Keywords: Heart failure with preserved ejection fraction (HFpEF); mechanical efficiency; pulmonary hypertension (PH); right ventricular dysfunction (RV dysfunction); ventriculo-arterial coupling

Submitted May 02, 2020. Accepted for publication Jun 04, 2020.

doi: $10.21037 / \mathrm{cdt}-20-479$

View this article at: http://dx.doi.org/10.21037/cdt-20-479 


\section{Introduction}

Pulmonary hypertension (PH) and right ventricular (RV) dysfunction are intrinsically linked to each other. The most frequent cause of $\mathrm{RV}$ dysfunction is $\mathrm{PH}$, and $\mathrm{RV}$ dysfunction is the most important determinant of clinical outcomes in patients with advanced $\mathrm{PH}(1-3)$.

Pulmonary arterial hypertension (PAH), classified as World Health Organization (WHO) Group $1 \mathrm{PH}$, has received the most attention from the scientific community, although it is a rare disease with an incidence of 2-5 cases per million adults (4). The pathophysiology of PAH is characterized by endothelial dysfunction, proliferation of smooth muscle cells, dysregulated inflammation and vasoconstriction leading to progressive diffuse remodeling and narrowing of the pulmonary arterial tree, and eventually pre-capillary $\mathrm{PH}(5)$.

$\mathrm{PH}$ related to left heart disease (WHO Group $2 \mathrm{PH}$ ) is the most frequent form of $\mathrm{PH}$ worldwide, representing at least $50 \%$ of all cases of $\mathrm{PH}(6,7)$. Heart Failure with preserved Ejection Fraction (HFpEF) is recognized as an important etiology of $\mathrm{PH}$, due to the demographic shift towards an aging population and the increasing prevalence of obesity, diabetes mellitus and systemic hypertension worldwide (8-10). HFpEF is defined as the presence of signs and symptoms of heart failure, and a preserved or "near normal" left ventricular (LV) ejection fraction ( $\geq 45 \%$ or $50 \%$ ) (11,12). The pathophysiology of HFpEF is multifactorial, including changes in $\mathrm{LV}$ structure, function, and abnormal cardiac reserve. In addition, peripheral abnormalities in the systemic vasculature, endothelium, adipocytes and skeletal muscle occur in the context of comorbidities such as obesity, hypertension, and metabolic syndrome $(13,14)$. The mechanism of $\mathrm{PH}$ in HFpEF (HFpEF-PH) relies primarily on pulmonary vascular congestion due to increased pulmonary venous pressure from chronically increased left-sided filling pressures (i.e., post-capillary $\mathrm{PH}$, characterized by pulmonary arterial wedge pressure or $\mathrm{LV}$ end-diastolic pressure $>15 \mathrm{mmHg}$ ). It also involves some degree of vasoconstriction related to hypoxia and endothelial dysfunction, and global remodeling of the pulmonary vascular tree (15), which translates in an elevated pulmonary vascular resistance (i.e., combined preand post-capillary $\mathrm{PH})$. Two clinical entities are therefore classically distinguished: isolated post-capillary $\mathrm{PH}$ and combined pre- and post-capillary PH $(16,17)$.

Patients with PAH or HFpEF-PH often have a similar clinical presentation [i.e., exertional dyspnea with signs of right heart failure (RHF)], along with echocardiographic findings of preserved $\mathrm{LV}$ ejection fraction, making the distinction between these two clinical entities challenging (18). Both PAH and HFpEF-PH are associated with an increased prevalence of RV dysfunction, which is a strong independent determinant of survival in both diseases (1-3,19-23). While some mechanisms of RV dysfunction are common (i.e., increased RV wall stress secondary to the increased afterload), other factors can contribute to RV dysfunction in either condition. As such, an understanding of the process of RV mechanics and function is fundamental.

In the present review, as part of the Special Issue on Right Ventricular Dysfunction in Cardiovascular Diagnosis and Therapy, we describe the concepts and physiology for the different components of RV mechanics, i.e., RV function, interventricular dependency and dyssynchrony, $\mathrm{RV}$ coupling to the pulmonary arterial circulation, RV diastology and cardiac efficiency (Figure 1). We then discuss the similarities and differences in RV dysfunction between $\mathrm{PAH}$ and HFpEF-PH in terms of prevalence, mechanisms and outcome prediction.

\section{RV dysfunction and dyssynchrony}

\section{$R V$ dysfunction}

$\mathrm{RV}$ dysfunction can be described as a change in $\mathrm{RV}$ mechanics altering the ability of the right ventricle to fill or eject properly to meet the metabolic demands. The extent of RV dysfunction varies depending on the stage of RHF (Figure 1) and alterations of RV mechanics can even precede development of symptoms in the early stage of RHF (23).

In $\mathrm{PH}, \mathrm{RV}$ dysfunction occurs when the right ventricle fails to adapt to the increased pressure load. Ventricular adaptation to pressure overload, refers to the process of preserving stroke volume (SV) without an increase in RV filling pressures (24). Initially, the right ventricle adapts to the increased pulmonary arterial load by enhancing muscle contractility and increasing wall thickness (i.e., RV hypertrophy) to decrease wall stress (according to Laplace's law) (25). This initial inotropic response is a process known as homeometric adaptation, by which the ventricle responds with an increase in myocardial inotropy $(26,27)$, and $\mathrm{SV}$ is restored without altering chamber geometry (24). However, if systolic function cannot be enhanced any further, RV dilation remains the only effective response to increased afterload, process known as heterometric adaptation, in which an increase in RV enddiastolic volume produces an equal increase in SV, thereby restoring SV and securing cardiac output $(24,28)$. As the 

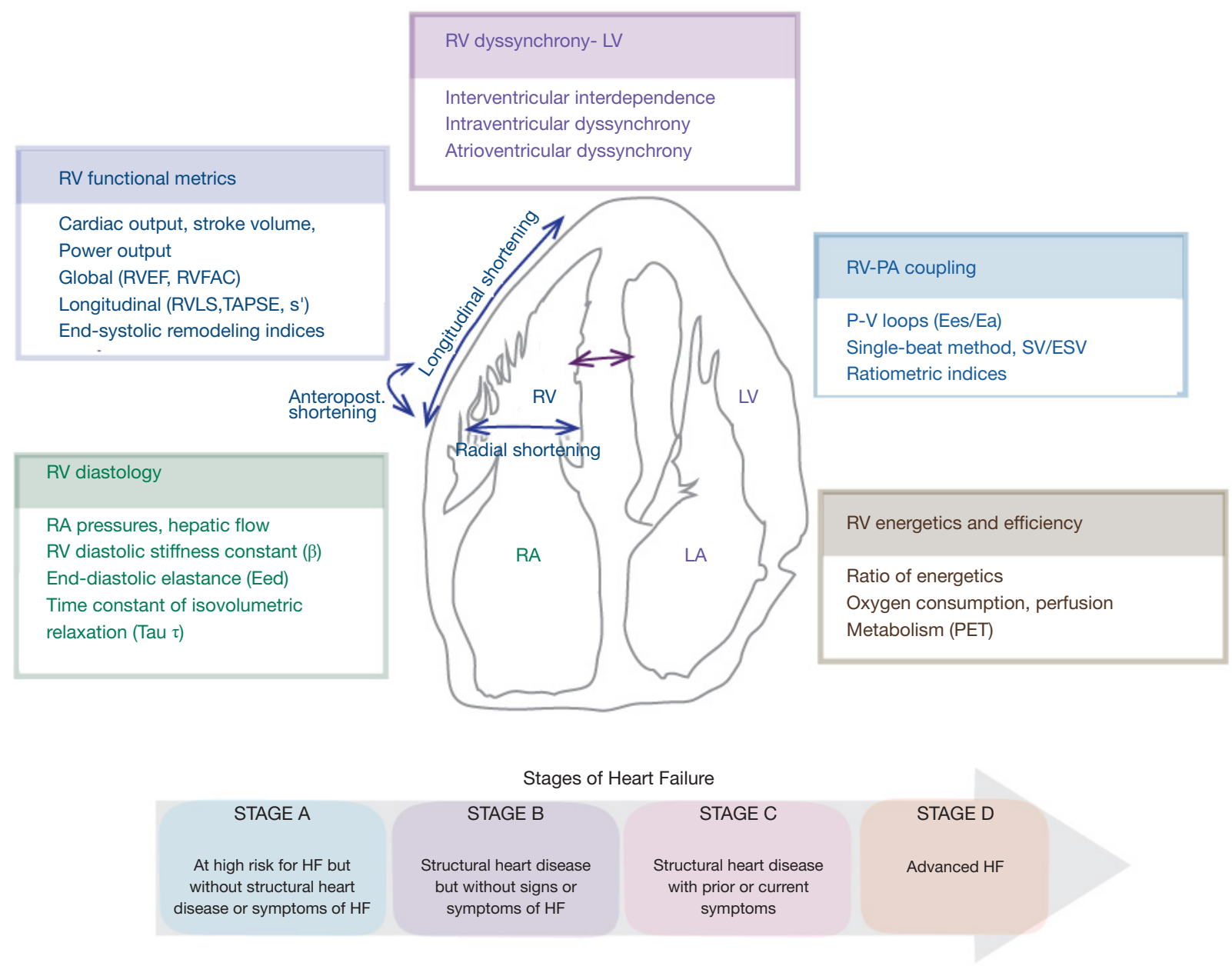

Figure 1 Graphical abstract. Components of right ventricular (RV) mechanics. ESV, end-systolic volume; HF, heart failure; LA, left atrium; LV, left ventricle; PET, positron emission tomography; P-V loops, pressure-volume loops; RA, right atrium; RV, right ventricle; RVEF, RV ejection fraction; RVFAC, RV fractional area change; RVLS, RV longitudinal strain; TAPSE, tricuspid annular plane systolic excursion; S', Tissue-Doppler tricuspid annular S' wave maximal velocity; SV, stroke volume.

disease progresses, further RV dilation is associated with leftward septal bowing, which compromises LV function and filling, further reducing SV (28).

\section{$R V$ mechanics}

Mechanics is the science of motion and flow dynamics. The study of RV mechanics includes (I) analysis of ventricular motion in the amplitude and time series domains (myocardial deformation, volumetric change and dyssynchrony), (II) analysis of the determinants of RV motion (contractility and loading components), (III) analysis of RV energetics and (IV) the study of ventricular flow dynamics (vortices and flow energetics).
Anatomically, the right ventricle is divided into three regions: RV inlet (represented by the tricuspid valve, chordae tendineae and papillary muscles, corresponding to the inflow region), RV trabeculated apical myocardium, and $\mathrm{RV}$ outlet (i.e., the infundibulum or conus, corresponding to the smooth myocardial outflow region) (29). The architecture of the RV myocardial fibers contributes to three different patterns of contraction: (I) longitudinal shortening with traction of the tricuspid annulus towards the apex; (II) transverse or radial shortening of the RV free wall ("bellows" effect) and (III) anteroposterior shortening of the chamber by stretching the free wall over the septum (30).

Until recently, longitudinal shortening was believed to contribute more to $\mathrm{RV}$ volumetric changes than the other 
components (radial and anteroposterior shortenings), contrary to the left ventricle (30). This has supported the wide use of RV longitudinal echocardiographic metrics [such as tricuspid annular plane systolic excursion (TAPSE), RV free-wall longitudinal strain (RVLS) or the tricuspid annular s' maximal velocity], as metrics of RV function (Figure 2). Echocardiographic-based TAPSE using M-mode (which has better temporal resolution than 2D mode) is widely used in clinical practice due to its simplicity. However, the reliability of TAPSE heavily depends on the quality of acquisition (requiring alignment of the tricuspid annulus motion with the M-mode cursor). Deformationbased imaging of RV global longitudinal strain and strain rate can be measured either using speckle-tracking echocardiography (31) or by manually tracing the lengths of the RV free-wall (32), as per the Lagrangian definition: (end-systolic length-end-diastolic length)/end-diastolic length, expressed in \%. Manual tracing is particularly useful in the presence of low-quality images. Both TAPSE and RVLS can be altered after cardiac surgery and do not accurately reflect $\mathrm{RV}$ dysfunction in the postoperative setting, which can instead be appreciated by metrics of global function, such as RV fractional area change (RVFAC) or ejection fraction (RVEF) (Figure 2) (33). Postoperative reduction in $\mathrm{RV}$ longitudinal performance may be related to pericardiotomy although additional mechanisms have been described (34), and can last for several months, despite the absence of change in global RV function parameters (35). See the review of Navaratnam et al. on perioperative RV dysfunction within this special issue (36).

While longitudinal shortening may account for the majority of RV systolic function in healthy individuals, recent studies have unraveled a similar importance of RV radial motion in PAH and HFpEF (30,37-39). Radial motion appears to correlate better with global function than longitudinal shortening in idiopathic PAH (37), while radial motion is relatively preserved in patients with Eisenmenger's syndrome (especially in post-tricuspid shunts) (40). In HFpEF, there also seems to be an early decrease in radial shortening (30), which differs from heart failure with reduced ejection fraction in which longitudinal motion (i.e., mitral annular plane systolic excursion) is usually more affected (38).

Data on pediatric RV dysfunction has been extensively reviewed elsewhere (41-43). Because of the fetal circulation and perinatal hemodynamic changes, the right ventricle of a newborn, infant and young child continues to have a high mass (RV hypertrophy) and low compliance, and the right ventricle can tolerate high levels of pressure afterload relatively well, so that both the right ventricle and the tricuspid valve annulus usually do not dilate substantially over several months. For that reason, infants and young children may not develop significant tricuspid regurgitation (TR) despite severe $\mathrm{PAH}$, and the severe RV pressure overload is often primarily diagnosed by assessing the end-systolic bowing of the interventricular septum towards the left ventricle. See the review of Santens $e t$ al. on congenital heart disease and RV dysfunction within this special issue (44).

The RV end-systolic remodeling index (RVESRI, defined as the length of the RV free-wall in end-systole divided by the septal length), is a useful indicator of RV remodeling and dilation in the setting of increased $\mathrm{RV}$ pressure load. A recent study showed that RVESRI was associated with hemodynamic metrics of disease severity and impaired functional capacity (45). Children with $\mathrm{PH}$, high pulmonary vascular resistance and impaired stroke work (i.e., ventricular-ventricular mismatch), had severe RV dysfunction and high incidence of adverse outcomes (46).

\section{Ventricular interdependence and dyssynchrony}

With the increase in systolic RV pressure relative to $\mathrm{LV}$ pressure and the progressive $\mathrm{RV}$ dilation, the interventricular septum flattens and deviates towards the left ventricle, impairing LV filling $(28,47,48)$, process known as interventricular dependence. Leftward septal bowing or septal flattening can be easily observed in cardiac magnetic resonance (CMR) short axis view or 2D echocardiographicparasternal short axis view, predominantly in end-systole in the setting of RV pressure overload (as in $\mathrm{PH}$ ) and measured using the LV end-systolic eccentricity index $(42,48-50)$ (Figure 2), or in end-diastole in the setting of RV volume overload. Interestingly, pediatric $\mathrm{PH}$ patients also have reduced LV strain, predominantly within the septum, which correlates with invasive hemodynamics, RV strain, and functional $\mathrm{PH}$ measures (51).

Another major component of $\mathrm{RV}$ dysfunction in $\mathrm{PH}$ is the presence of interventricular, intraventricular, and atrioventricular dyssynchrony, which have been better studied in the setting of pre-capillary PH. Efficient cardiac output is achieved by synchronous contraction and relaxation of the two ventricles. In the presence of $\mathrm{PH}$, there is prolonged contraction of the right ventricle, which continues to eject while the left ventricle is already relaxing, with resultant leftward septal bowing, and interventricular 

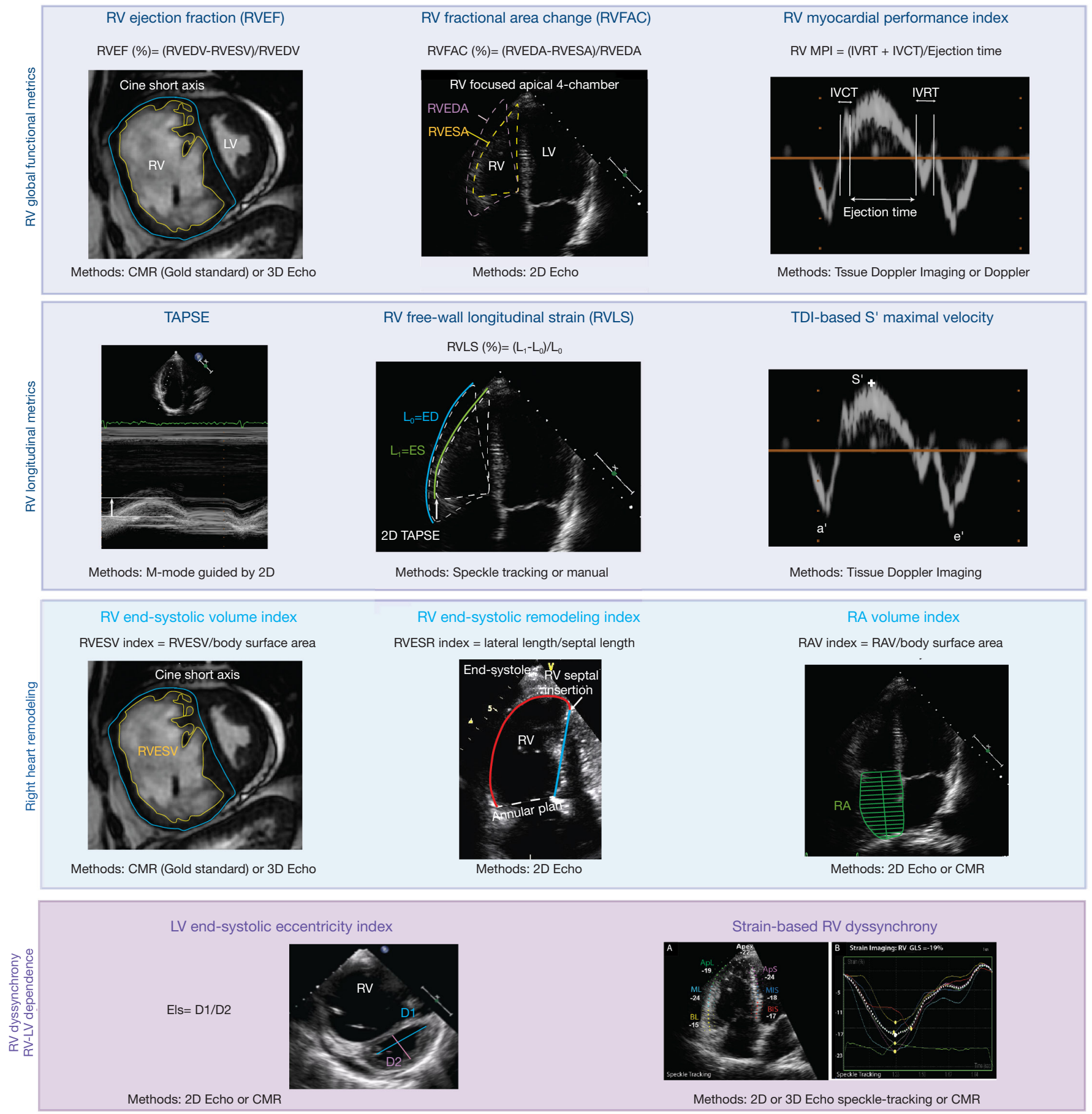

Figure 2 Right ventricular clinical imaging metrics. 2D Echo, two-dimensional echocardiography; 3D, three-dimensional echocardiography; CMR, cardiac magnetic resonance imaging; EIs, end-systolic eccentricity index; IVCT, isovolumetric contraction time; IVRT, isovolumetric relaxation time; LV, left ventricular; RA, right atrium; RV, right ventricular; TAPSE, tricuspid annular plane systolic excursion; TDI, tissue doppler imaging. 
dyssynchrony (49,52). The timing of RV systolic contraction and relaxation of myocardial segments is heterogeneous, partially due to non-uniform distribution of wall stress within the right ventricle (intraventricular dyssynchrony) $(53,54)$. Both the delayed systolic septal contraction and relaxation in comparison to the RV lateral (or free-wall) contraction contribute to the inefficiency of RV contraction in patients with $\mathrm{PH}$. Both RV intra- and interventricular dyssynchrony can be quantified by strain analysis using either 2D speckle-tracking echocardiography (as illustrated in Figure 2) or CMR $(52,55)$. Time to peak systolic strain is a marker of dyssynchrony, as it reflects RV post-systolic shortening with inefficient contraction occurring after pulmonary valve closure. A study using speckle-tracking echocardiography found that patients with idiopathic PAH and a prolonged time to peak systolic strain had more advanced disease and decreased exercise capacity (52). In multivariate analysis, it was noted that RV dyssynchrony was associated with RV dilation, diastolic septal flattening and a lower RV wall thickness/end-diastolic volume ratio. RV pacing (which is frequently associated with RV dysfunction in patients with HFpEF) also contributes to dyssynchrony. Similarly, atrial fibrillation, which has been associated with RV dysfunction in HFpEF, causes atrioventricular dyssynchrony that further impairs RV filling.

Overall, many non-invasive imaging metrics of RV remodeling and function can be clinically used (Figure 2). Interestingly, these metrics of RV function (such as RVFAC and TAPSE) actually reflect the coupling between the right ventricle and its increased afterload, as demonstrated in a piglet model of $\mathrm{PH}$ (56). See the review of Truong et al. on non-invasive imaging of RV dysfunction within this special issue (57).

\section{Pressure-volume loop analysis and ventriculo- arterial coupling}

The key of RV adaptation in $\mathrm{PH}$ is the ability of the right heart to balance RV contractility with the pulmonary arterial vascular load, known as ventriculo-arterial coupling. From a physiologic perspective, pressure-volume (PV) loop analysis is considered the reference method to analyze the determinants of cardiac contraction and filling and therefore assess ventricular-arterial coupling $(3,23)$.

\section{Systolic component of pressure-volume loop analysis}

Analysis of the PV loop allows for an accurate description of the RV-pulmonary arterial (RV-PA) system as a unit, since it accounts for the interaction of the intrinsic contractile capacity of the RV subsystem (represented by end-systolic elastance, or Ees) in relationship to the load of the pulmonary vascular subsystem (described by effective arterial elastance, or Ea) (Figure 3). The relationship between these two subsystems is described by the ratio between ventricular elastance and arterial elastance, or Ees/ $\mathrm{Ea}$, known as the coupling ratio $(3,21,23,28,58)$.

From a mechanical perspective, optimal or preserved coupling refers to effective energy transfer from the $\mathrm{RV}$ to the pulmonary arterial tree, meaning that RV-PA flow occurs at minimal energy cost (28). Ees is a loadindependent descriptor of the intrinsic RV contractile capacity (24). The derivation of Ees is based on the concept of time-varying elastance (59). By obtaining different sets of PV loops at decreasing levels of preload (60), it is possible to estimate Ees as the end-systolic pressure-volume relation (ESPVR) slope, which connects the different endsystolic pressure and volume points (24) (Figure 3). Ea is a descriptor of total circulatory load, accounting for both resistive and pulsatile load, and is calculated as the ratio of end-systolic pressure (ESP) and SV, or ESP/SV (61).

\section{Multibeat method}

The standard methodology for PV loop analysis is performed by obtaining different sets of PV loops at different levels of preload (Figure 3). It requires simultaneous measurement of RV volumes and pressures (usually by means of a RV conductance catheter), and different levels of preload are obtained by either partial occlusion of the inferior vena cava $(58,62)$ or through Valsalva maneuvers $(63,64)$. While this methodology, known as the multibeat method, is feasible in humans (6366), its technical complexity renders it impractical for daily clinical use. As such, simplified "single beat" methods have been proposed $(67,68)$, although with different assumptions and limitations, which are important to consider (69).

\section{Single beat method}

The most common single beat method relies on the assumption that the Ees slope will eventually continue until the theoretical point of maximal isovolumetric pressure, or Pmax. Pmax is estimated from a sinusoidal curve fit of the RV pressure waveform during early isovolumetric contraction and late isovolumetric relaxation $(67,70,71)$. By 


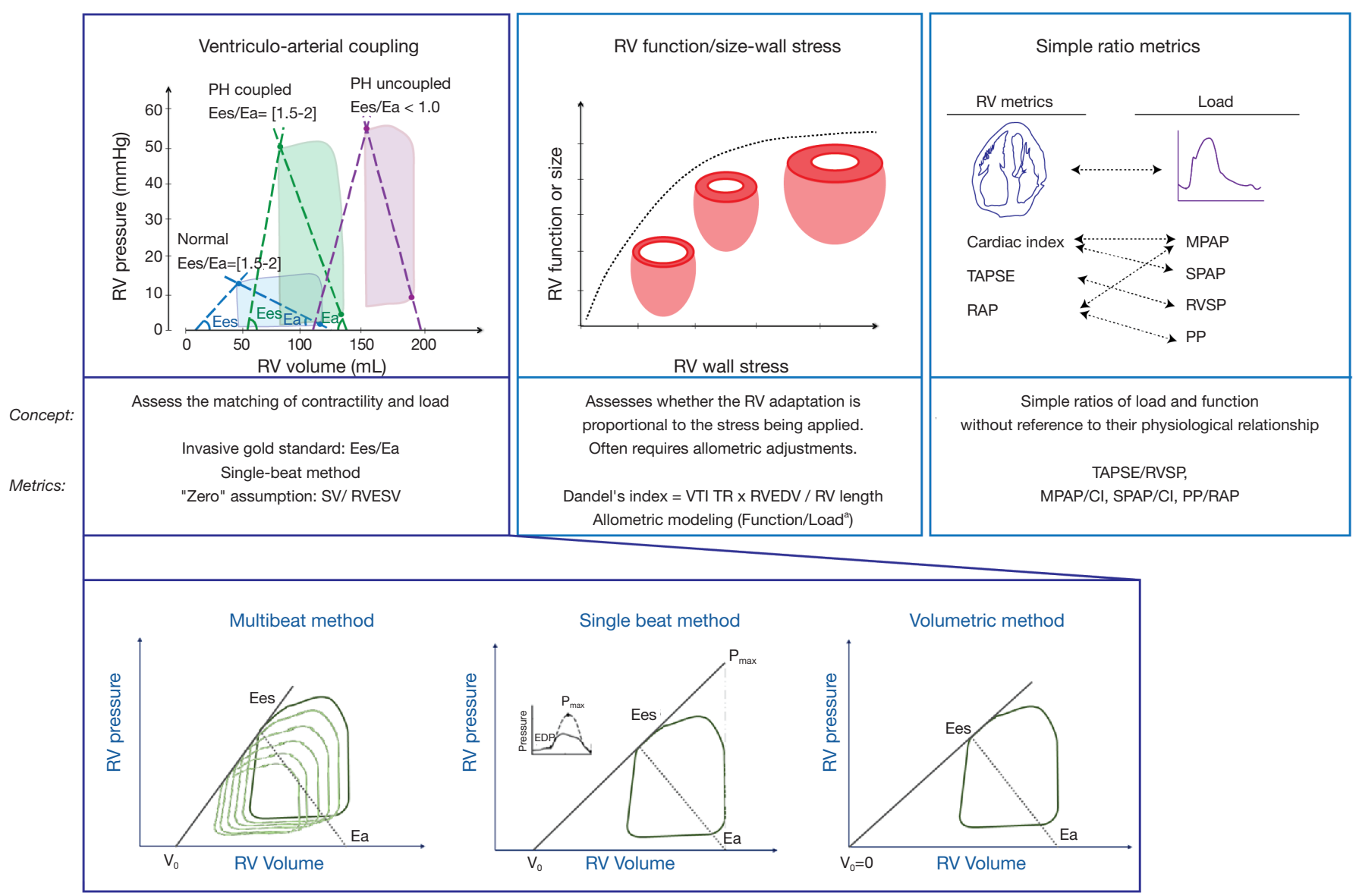

Figure 3 Right ventricular-pulmonary arterial coupling. Upper panels (left to right): pressure-volume loop analysis and estimation of ventriculo-arterial coupling; correlation between RV wall stress and RV dilation/size and representation of different ratio metric indices of RV load and function. Lower panels (left to right): Methods for estimation of ventriculo-arterial coupling. The multibeat method requires obtaining different sets of pressure-volume loops at decreasing levels of preload (left). In the single beat method, the RV pressure waveform tracing is used for estimation of Pmax (center). In the volumetric method (right), $\mathrm{V}_{0}$ is assumed to be equal to zero, and Ees is estimated by the ratio of end-systolic pressure to end-systolic volume.

estimating Pmax, only one set of PV loops is needed, and Ees is estimated as (Pmax-ESP)/SV, while Ea is estimated as ESP/SV. The assumptions behind this approach are the linearity of the relationship Pmax-ESP, and the determination of Pmax from the RV pressure waveform trace, which assumes that ventricular contraction without ejection (isovolumetric contraction) would have the same ESPVR as a normal ejecting beat (24). Furthermore, the methodologies for estimation of Pmax were developed in healthy dogs (67), and then adapted to humans, although never formally evaluated in patients with advanced $\mathrm{PH}$ $(65,69)$. Another assumption is the estimation of the RV ESP point. Simplified quantifications of Ees use time- independent PV relations to construct ESPVR near endsystole, such as the maximum pressure/volume ratio or end-ejection (dicrotic notch) pressure/volume (72). These different estimates correlate well with maximal elastance in the left heart, because end-ejection has a close temporal relation to the point of peak systolic elastance $(73,74)$. However, RV ESPVR relations near end-ejection (i.e., dicrotic notch) tend to underestimate ventricular elastance due to the wide temporal separation between peak systolic elastance and end-ejection (59). Slopes derived from the maximum pressure/volume ratio seem to have better correlation with maximal RV elastance, and it could be a better metric for estimation of ESPVR (72). However, 
most studies have used different estimates of RV ESP near end-ejection, such as mean pulmonary artery pressure (mPAP) (75), RV systolic pressure (76), or the RV pressure $30 \mathrm{~ms}$ before minimum $\mathrm{dP} / \mathrm{dt}(77,78)$. A recent study compared the performance of estimating RV ESP by use of a conductance catheter versus using $\mathrm{mPAP}$ as a surrogate of RV ESP. It was shown that using mPAP tended to underestimate RV ESP, especially in patients with higher pulmonary pressures (65). The correlation between the single beat method and the gold standard multibeat method remains unclear, especially in patients with advanced $\mathrm{PH}$. A small study comparing both methods in patients with PAH suggested optimal correlation $(\mathrm{r}=0.9, \mathrm{P}<0.001)$, with minimal bias and acceptable levels of agreement, but the small sample size warrants caution on the interpretation of these results (79).

\section{Volumetric method}

An even more simplified methodology is commonly referred to as the volumetric method, where Ees is approximated as the ratio ESP/end-systolic volume (ESV), and Ea, as ESP/ $\mathrm{SV}$. The coupling ratio Ees/Ea has a common pressure term ESP, and it can be simplified as SV/ESV $(80,81)$. The main assumption of this method is that the horizontal intercept $\mathrm{V}_{0}$ equals to zero, assumption not met in cases of severe $\mathrm{PH}$ and RV failure (82). A benefit of the volumetric method is that relies mainly on estimation of volumes, omitting the need for invasive measurements of RV pressures (81). Figure 3 provides a graphic representation of the multibeat, single beat and volumetric method.

\section{Non-invasive surrogates of coupling}

Several ratio metrics have been proposed as surrogates of right ventriculo-arterial coupling, which mainly refer to combined indices of $\mathrm{RV}$ function or chamber size, divided by a metric of load (Figure 3). Some of the most common metrics are the ratio of TAPSE divided by systolic pulmonary artery pressure (sPAP) $(83,84)$, where sPAP is estimated by echocardiography, and the pulmonary artery pulsatility index [pulmonary artery pulse pressure divided by right atrial pressure (RAP)] $(85,86)$. While having the advantage of being simple ratios, they do not follow an allometric physiological relation between RV function and afterload (87-89). Also, these ratios do not provide information on load-independent ventricular function or total load, which are functional components of ventriculo- arterial coupling. For instance, a similar decreased TAPSE/ sPAP ratio can be obtained by a significant decrease in TAPSE (in the presence of normal or slightly elevated sPAP, which reflects a poor RV adaptation to load) or by a significant increase in SPAP (in the presence of a maintained TAPSE, which reflects an adequate RV adaptation to increases sPAP). Furthermore, TAPSE per se is already a marker of coupling (56).

\section{RV diastology}

Diastolic function is a major determinant of ventricular performance. Diastolic filling depends on myocardial relaxation, restoring forces generated by elastic energy stored within the myocardium and atrial contraction (90). Diastolic dysfunction is the result of impaired ventricular relaxation, with or without abnormal restoring forces (and early diastolic suction), as well as increased ventricular chamber stiffness, with the resultant increase in cardiac filling pressures (91). Impaired diastolic function precedes systolic ventricular dysfunction and also influences the performance of the contralateral ventricle via ventricular interdependence (92).

Diastolic filling is composed of different phases, with an initial period of isovolumetric relaxation, followed by an early rapid diastolic filling period (E-wave), a plateau period, and finally a phase of late filling due to the atrial contraction (A-wave) (93). Since RV diastology is composed of different phases, it cannot be described by a unique metric. Different metrics that have been used to define RV diastolic function include (I) RAP and RV end-diastolic pressure, (II) RV filling profiles (based on $\mathrm{E}$ and $\mathrm{A}$ waves), (III) relaxation-phase indices [isovolumic relaxation time (IVRT), $\mathrm{dP} / \mathrm{dt}$ minimum, or the time constant of isovolumic pressure decay], and (IV) passive chamber characteristics such as RV stiffness, identified by PV loop analysis (29).

RAP or RV end-diastolic pressure can be measured directly during right heart catheterization or estimated noninvasively by assessing the diameter and collapsibility of the inferior vena cava (94). The increase in RAP can also be transmitted backwards to the hepatic, portal and renal veins, and changes in flow pattern can be identified by Doppler analysis (95) (Figure 4).

Different filling patterns can be described with pulsedwave Doppler analysis of the transtricuspid inflow into the RV $(93,96)$. Early RV diastolic dysfunction is characterized by a decrease in the E-wave reflecting impaired RV relaxation, while late stages of $\mathrm{RV}$ diastolic dysfunction 


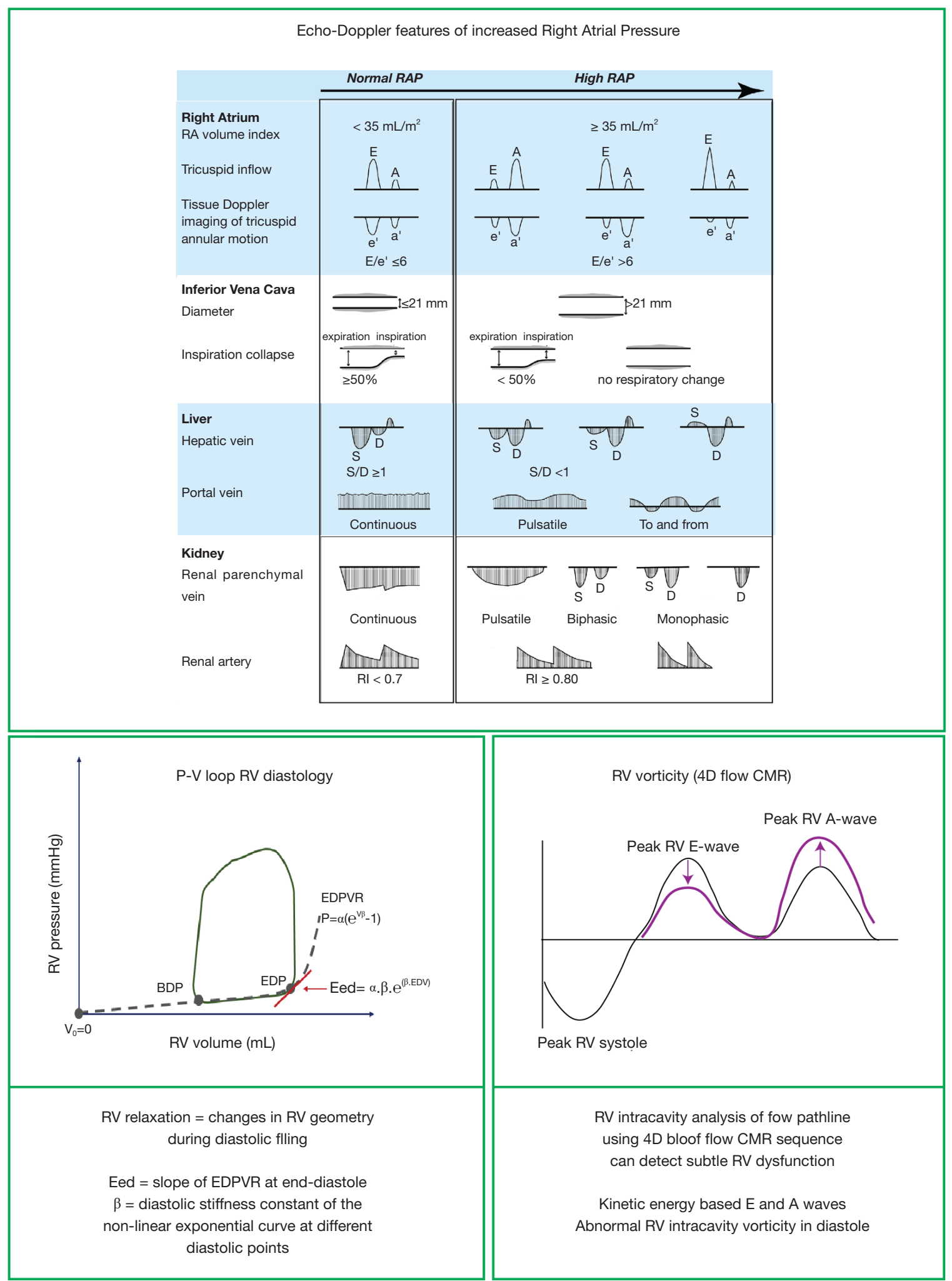

Figure 4 Right ventricular (RV) diastology. BDP, beginning of diastolic pressure; CMR, cardiac magnetic resonance; Eed, ventricular enddiastolic elastance; EDP, end-diastolic pressure; EDPVR, end-diastolic pressure-volume relationship; P-V, pressure-volume loops; $\mathrm{V}_{0}$, Volume intercept at zero pressure. Adapted with permission from Tang et al. 
are characterized by an increase E/A ratio reflecting RV chamber stiffness (Figure 4). Similar to the left ventricle, an increased ratio of the transtricuspid $\mathrm{E}$ wave and the Tissue Doppler Imaging-derived e' wave $>6$ is a marker of increased RV filling pressures (95).

Among relaxation-phase indices, the IVRT can be noninvasively determined using Tissue Doppler Imaging at the lateral tricuspid annulus (Figure 2). An increased IVRT reflects impaired relaxation and increased RAP, particularly in $\mathrm{PH}$ (97-99). However, this index is highly dependent on heart rate and preload, and becomes pseudo-normalized in the setting of RAP elevations, which limits its prognostic value and clinical implementation (100). The time constant of isovolumetric relaxation (Tau, $\tau$ ) is another metric of $\mathrm{RV}$ relaxation (101). It is calculated from invasive derivatives of $\mathrm{RV}$ maximum (dP/dt max) and minimum (dP/dt min) pressure change, and has been reported to be increased $(53 \pm 32 \mathrm{~ms}$, compared to $31 \pm 13 \mathrm{~ms}, \mathrm{P}=0.04)$ in patients with $\mathrm{PH}$ from diverse etiologies $(102,103)$.

\section{Diastolic component of pressure-volume loop analysis}

Information of load-independent RV diastology can be obtained by PV loop analysis, with estimation of the diastolic stiffness constant $\beta$ and end-diastolic elastance (Eed). The $\beta$ coefficient is obtained by fitting a nonlinear exponential curve through the diastolic $\mathrm{PV}$ points at the beginning of diastole and end-diastole (end-diastolic PV relation, or EDPVR). $\beta$ can be estimated by the formula $\mathrm{P}=\alpha\left(\mathrm{e}^{\mathrm{V} \beta}-1\right)$, where $\mathrm{P}=$ pressure and $\mathrm{V}=$ volume (104), as shown on Figure 4. Similarly, Eed is calculated by the slope of EDPVR at end-diastole, using the formula $\alpha . \beta . e^{(\beta .}$ EDV), where EDV = end-diastolic volume, $\alpha=$ curve fit and $\beta=$ stiffness constant. Increased Eed was associated with decreased survival in a study of patients with $\mathrm{PAH}$ [hazard ratio $2.24,95 \% \mathrm{CI}(1.05-4.80), \mathrm{P}=0.037$ ] (105).

\section{Novel methods to identify $R V$ diastolic dysfunction}

Novel non-invasive imaging technology, such as 4-dimensional flow cardiovascular magnetic resonance (4D flow CMR), has brought new light on RV diastology, enabling detection and visualization of dynamic right heart flow patterns $(106,107)$. 4D flow CMR is a new sequence that allows acquisition and high-fidelity spatial and temporal visualization of three-dimensional timeresolved blood flow and velocities in all directions for each temporal phase of the cardiac cycle (108) and enabling quantification of vorticity (i.e., localized spinning motion of blood at certain points). Two pilot studies on RV intracavity diastolic flow described changes in RV vorticity as markers of RV dysfunction in patients with PAH and/or RV diastolic dysfunction (Figure 4). Patients with PAH had alterations in $\mathrm{E}$ - and $\mathrm{A}$-wave vorticity (increased right heart $\mathrm{A}$-wave velocity, decreased spatially integrated $\mathrm{E}$-wave velocity and overall decreased E/A ratio) as compared to controls (109). Another study showed that patients with RV diastolic dysfunction presented with decreased early diastole total vorticity in the RV chamber (110). In a study conducted in 22 patients with $L V$ disease, analysis of the RV intracavity flow pathline with evidence of decreased kinetic energy in end-diastole (using 4D flow CMR) was able to detect early RV dysfunction which was not identified using standard CMR (111). Further studies need to demonstrate the reproducibility and clinical incremental value of $4 \mathrm{D}$ flow CMR based RV diastolic assessment for early detection of PAH or HFpEF-PH.

\section{RV energetics: a world of work and efficiency}

\section{$R V$ efficiency, power and oxygen consumption}

The right ventricle is a pulsatile pump, and its efficiency depends on proper hemodynamic coupling with the pulmonary circulation (24). Optimal coupling guarantees that most of the RV pump energy is effectively transferred into blood flow (112). In a highly efficient RV, all energy input into the ventricle would be transformed into useful mechanical work. But in reality, the total contractile power (or work) generated by the contractile pump is only partially turned into hydraulic power (power transferred to blood flow) and most of it is used to store energy in cardiomyocytes during diastole, as well as ensuring cell integrity and homeostasis (113). Of the total hydraulic power, only a fraction contributes to net forward blood flow (steady power) with the rest spent on oscillations in blood flow (oscillatory power) (24).

$\mathrm{RV}$ efficiency refers to the balance between efficient energy use (work for blood flow) and $\mathrm{O}_{2}$ consumed, or the ratio of steady hydraulic power over $\mathrm{O}_{2}$ consumption (114,115), as illustrated by Figure 5. In normal subjects, RV efficiency is usually around $25 \%$, as compared to less than $15 \%$ in patients with advanced $\mathrm{PH}(28,116)$.

The right ventricle relies on aerobic metabolism for generation of energy $(115,117)$. As such, the balance between myocardial $\mathrm{O}_{2}$ demand (or consumption) and supply is 

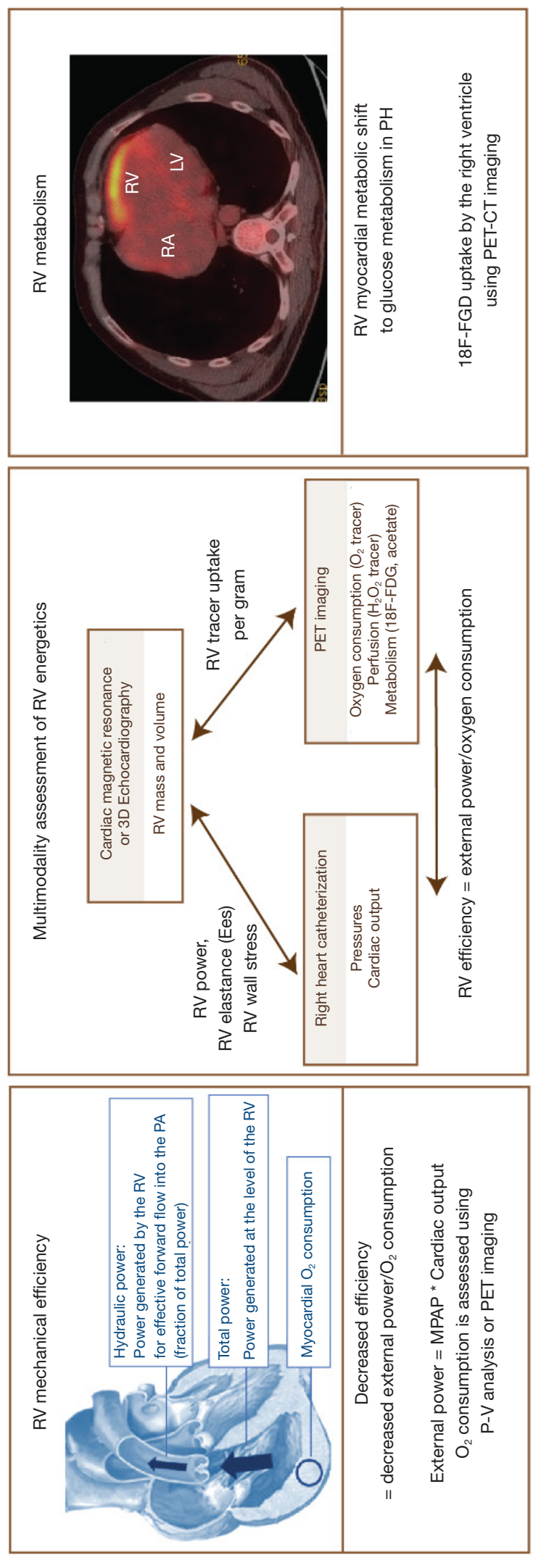

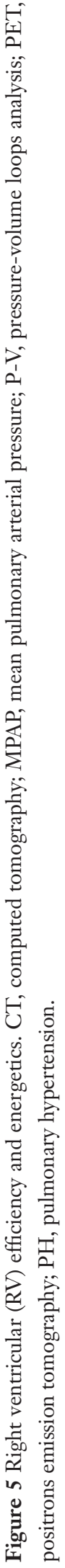

crucial for RV performance. In theory, the increase in RV $\mathrm{O}_{2}$ consumption in $\mathrm{PH}$ (due to tachycardia, RV hypertrophy and increased wall stress) should be accommodated by either increasing the fraction of $\mathrm{O}_{2}$ extracted from blood or increasing myocardial perfusion (24). However, myocardial perfusion is limited in $\mathrm{PH}$, which contributes to $\mathrm{RV}$ hibernation and ischemia. Under physiologic conditions, the RV myocardium is perfused both in diastole and systole, because of the significant pressure gradient between the aorta and the right ventricle. In $\mathrm{PH}$, the systolic pressure gradient between the aorta and the right ventricle may be close to zero (or even negative, as seen in young patients with suprasystemic PAH). Furthermore, the diastolic pressure gradient between the aorta and the right ventricle may also be reduced, decreasing blood flow through the right coronary artery and its downstream (118). In addition, capillary rarefaction has been observed in right ventricles exposed to increased afterload, associated with impaired angiogenesis $(119,120)$. In patients with HFpEF (with or without $\mathrm{PH}$ ), presence of epicardial obstructive coronary artery disease or microvascular disease (related to comorbidities such as advanced age, hypertension, diabetes or obesity) and endothelial dysfunction also contribute to $\mathrm{RV}$ hibernation and ischemia (11).

Simultaneous pressure and flow measurements (i.e., vascular impedance), allow for estimation of total hydraulic power, by combining pressure and kinetic power, as described elsewhere (121). Steady hydraulic power output (also known as external power) can be calculated as mPAP $x$ cardiac output (113), and the oscillatory hydraulic component is obtained as the difference between total power and steady power (24).

Ventricular efficiency can also be estimated with PV-loop analysis. Energy generated by the heart can be divided into actual produced energy (external work) and potential energy (122). External work can be delineated as the area contained within the PV-loop (115). The area under the curve on the left side of external work and confined by the ESPVR and the EDPVR slopes represents potential energy. The total $\mathrm{PV}$ area (sum of external work and potential energy) equals total mechanical energy generated by the heart per beat $(115,122)$.

Ventricular $\mathrm{O}_{2}$ supply and consumption can be assessed (I) invasively by direct measurements of coronary blood flow and calculation of the arterio-venous $\mathrm{O}_{2}$ difference in the coronary circulation, and (II) non-invasively using positron emission tomography (PET) imaging with $\mathrm{O}_{2}$ tracers or with carbon-11-labeled acetate (11C-acetate). Activity of 
the tracer is proportional to myocardial blood flow, and the tracer clearing rate correlates closely with $\mathrm{O}_{2}$ consumption $(115,123)$.

Because RV efficiency is complex to derive and requires the measurement of $\mathrm{O}_{2}$ consumption by means of PET imaging, a surrogate measure is the Ees/Ea ratio (28). Maximal transfer of potential energy from one elastic chamber to another occurs when these chambers have equal elastance. A study on isolated left ventricles showed that mechanical energy transfer from the RV to the pulmonary vascular subsystem was maximal (highly efficient), when the Ees and Ea slopes were equal to one another (124). The optimal Ees/Ea coupling of the RV to afterload for maximal efficiency is estimated to be around 1.5 (28), although based on extrapolation of LV data.

\section{RV metabolism}

In $\mathrm{PH}$, several metabolic changes occur in the right ventricle, particularly at the mitochondrial level, which affect RV efficiency (125). Glycolysis and glucose oxidation become uncoupled, leading to a cancer-like metabolic cellular phenotype. The Warburg effect, evident both in cancer cells and in pressure-overloaded RV cardiomyocytes describes predominant energy generation by glycolysis, instead of fatty acid oxidation (FAO) despite sufficient supply of oxygen (126). In RV pressure overload and dysfunction, mitochondrial FAO is inhibited (120), and there is a metabolic switch to use of glucose as energy source $(120,127,128)$.

Glucose uptake can be visualized using 18F-FDG-PET imaging (120). A healthy right ventricle normally does not take up significant amounts of $18 \mathrm{~F}-\mathrm{FDG}$, while in $\mathrm{PH}$ patients, the hypertrophic right ventricle has increased uptake of the tracer as illustrated in Figure 5. 18F-FDG RV glucose uptake has been shown to correlate with RVEF measured by CMR $(\mathrm{r}=-0.54, \mathrm{P}<0.01)$ in 23 patients with $\mathrm{PH}$ (87\% with PAH) (129). See the review of Agrawal et al. on molecular mechanisms of RV dysfunction within this special issue (130).

\section{Similarities and differences between PAH and HFpEF}

Prevalence and mechanisms of $R V$ dysfunction in $P A H$ vs. HFPEF

Determining the prevalence of RV dysfunction in patients with $\mathrm{PAH}$ or $\mathrm{HFpEF}$ is challenging as it varies widely according to the metric used and the type of cohort studied (Table 1). Nevertheless, the presence of RV dysfunction appears to be a common feature in both diseases.

While increased afterload and wall stress is a major cause of RV dysfunction in patients with PAH and HFpEF-PH, as detailed in previous chapters, other mechanisms can lead to RV alterations in these two conditions. In patients with HFpEF, those with RV dysfunction have more epicardial coronary disease and microvascular disease, endothelial dysfunction and fibrosis, renal dysfunction, arrhythmias (such as atrial fibrillation in the context of aging and hypertension), RV pacing ( $R V$ dyssynchrony, aggravation of TR) and systemic low-grade inflammation than those without RV dysfunction (131-133). Interestingly, both $\mathrm{PAH}$ and HFpEF-PH have emerged in the past decade as systemic diseases beyond the primary organ disease (lung and heart respectively) (134). Strong evidence is emerging on their association with systemic dysregulated inflammation $(13,135)$, endothelial dysfunction and low ability of the skeletal muscles for $\mathrm{O}_{2}$ extraction, leading to the poor functional state of patients with $\mathrm{PAH}$ and HFpEF (136-139). Further studies are needed to better investigate the role of systemic inflammation on the right ventricle of patients with $\mathrm{PAH}$ or HFpEF.

\section{Comparative characteristics of $R V$ dysfunction in $P A H$ and $\mathrm{HFpEF}$}

The comparative mechanics of RV dysfunction in PAH and HFpEF are illustrated in Figure 6. The decrease in radial shortening is an early feature in both conditions (30). Chamber geometry varies in $\mathrm{PAH}$ and HFpEF. RV dilatation is less pronounced in HFpEF-PH in comparison to PAH (RV size can be used to distinguish between patients with pre-capillary and post-capillary $\mathrm{PH}(131,140,141)$. The left heart phenotype also differs, in particular with left atrial dilatation in HFpEF (Figure 6).

Changes in RV morphology and function can be used for detection of $\mathrm{PH}$ in these patients. Echocardiographic strategies of $\mathrm{PH}$ detection primarily rely on measurement of the TR maximal velocity, which associated to the estimated RAP, allows for non-invasive estimation of the RV systolic pressure (16). The TR maximal velocity or the estimated RV systolic pressure have been shown to be highly correlated to invasive systolic pressure measurements in the presence of an interpretable TR signal and when particular care is given to the quality of the acquisition and 
Table 1 Comparative prevalence and prognostic value of right ventricular dysfunction in selected studies conducted on patients with pulmonary arterial hypertension and in those with heart failure preserved ejection fraction

\begin{tabular}{|c|c|c|c|c|}
\hline $\begin{array}{l}\text { First author, journal, } \\
\text { year }\end{array}$ & Number & $\begin{array}{l}\text { RV dysfunction } \\
\text { criteria }\end{array}$ & Prevalence of RV dysfunction & Link with outcomes \\
\hline \multicolumn{5}{|c|}{ Pulmonary arterial hypertension } \\
\hline $\begin{array}{l}\text { Van de Veerdonk } \\
\text { et al. JACC, } 2011\end{array}$ & $110 \mathrm{PAH}$ & RVEF by CMR & $50 \%$ with RVEF <36\% & $\begin{array}{l}\text { During a } 47 \text {-month FU, RVEF was associated } \\
\text { with mortality independently from pulmonary } \\
\text { vascular resistance. Changes in RVEF at } 1 \text { year } \\
\text { were also associated with survival }\end{array}$ \\
\hline $\begin{array}{l}\text { Ryo et al. } \\
\text { Circulation: CV } \\
\text { Imaging, } 2015\end{array}$ & $\begin{array}{l}92 \text { patients with } \\
\text { pre-capillary } \mathrm{PH}\end{array}$ & $\begin{array}{l}\text { RV end-systolic } \\
\text { volume index by } \\
\text { 3D echo }\end{array}$ & $\begin{array}{l}50 \% \text { with TAPSE }<19 \mathrm{~mm} \\
50 \% \text { with 3D RVEF }<33 \% \\
50 \% \text { with 3D RV global area } \\
\text { strain >-21\% }\end{array}$ & $\begin{array}{l}\text { During the 6-month FU, RV end-systolic volume } \\
\text { indexed on body surface area was associated } \\
\text { with } \mathrm{PH} \text {-related hospitalization, death, or lung } \\
\text { surgery (lung transplantation or pulmonary } \\
\text { endarterectomy) }\end{array}$ \\
\hline $\begin{array}{l}\text { Amsallem et al. } \\
\text { Circulation: } \mathrm{CV} \\
\text { Imaging, } 2017\end{array}$ & $228 \mathrm{PAH}$ & $\begin{array}{l}\text { RVESRI; RVLS; } \\
\text { RVFAC; TAPSE }\end{array}$ & $\begin{array}{l}72 \% \text { had a RVLS }>-20 \% \\
88 \% \text { had a RVFAC }<35 \% \\
53 \% \text { had a TAPSE }<18 \mathrm{~mm}\end{array}$ & $\begin{array}{l}\text { During the 5-year FU, RVESRI predicted clinical } \\
\text { worsening (death, transplant or readmission for } \\
\text { heart failure) in addition to NYHA class and NT- } \\
\text { proBNP levels. RVESRI was more reproducible } \\
\text { and prognostic than RVLS, and incremental to } \\
\text { the REVEAL score. }\end{array}$ \\
\hline $\begin{array}{l}\text { Burke et al. } \\
\text { Circulation: Heart } \\
\text { Failure, } 2013\end{array}$ & 419 HFpEF & $\begin{array}{l}\text { TAPSE; RVFAC; } \\
\text { RVESAI; RVEDAI }\end{array}$ & $\begin{array}{l}28 \% \text { had TAPSE }<16 \mathrm{~mm} \\
15 \% \text { had } \mathrm{RVFAC}<35 \%\end{array}$ & $\begin{array}{l}\text { During an 18-month FU, TAPSE was a predictor } \\
\text { of outcome independently of pulmonary } \\
\text { pressures }\end{array}$ \\
\hline $\begin{array}{l}\text { Mohammed et al. } \\
\text { Circulation, } 2014\end{array}$ & 562 HFpEF & $\begin{array}{l}\text { TAPSE; } \\
\text { Semiquantitative } \\
\text { RV function }\end{array}$ & $50 \%$ had TAPSE $<17 \mathrm{~mm}$ & $\begin{array}{l}\text { During the 8-year FU, semiquantitative RV } \\
\text { dysfunction (or TAPSE) was associated with } \\
\text { mortality, independently from pulmonary } \\
\text { pressures }\end{array}$ \\
\hline $\begin{array}{l}\text { Melenovsky et al. } \\
\text { Eur Heart J, } 2014\end{array}$ & $96 \mathrm{HFpEF}$ & RVFAC & $33 \%$ had RVFAC $<35 \%$ & $\begin{array}{l}\text { During a } 529 \text {-day FU, RVFAC }<35 \% \text { was the } \\
\text { strongest predictor of death }\end{array}$ \\
\hline $\begin{array}{l}\text { Aschauer et al. Eur } \\
\text { J Heart Failure, } \\
2015\end{array}$ & 171 HFpEF & RVEF; by CMR & $19 \%$ had RVEF <45\% & $\begin{array}{l}\text { During a } 573 \text {-day FU, RVEF }<45 \% \text { was a } \\
\text { predictor of cardiac death or admission for heart } \\
\text { failure, independently from diabetes, } 6 \text {-minute } \\
\text { walk distance and systolic pulmonary arterial } \\
\text { pressure }\end{array}$ \\
\hline
\end{tabular}

Table 1 (continued) 
Table 1 (continued)

\begin{tabular}{|c|c|c|c|c|}
\hline $\begin{array}{l}\text { First author, journal, } \\
\text { year }\end{array}$ & $\mathrm{n}$ & $\begin{array}{l}\text { RV dysfunction } \\
\text { criteria }\end{array}$ & Prevalence of RV dysfunction & Link with outcomes \\
\hline $\begin{array}{l}\text { Morris et al. Eur } \\
\text { H J: CV Imaging, } \\
2017\end{array}$ & 218 HFpEF & $\begin{array}{l}\text { RV strain (global } \\
\text { and free-wall); } \\
\text { TAPSE; RVFAC; S' }\end{array}$ & $50 \%$ had TAPSE $<19 \mathrm{~mm}$ & $\begin{array}{l}\text { RV global and free wall systolic strain were } \\
\text { significantly linked to the symptomatic status of } \\
\text { the patient. No data on outcomes }\end{array}$ \\
\hline $\begin{array}{l}\text { Hussain et al. } \\
\text { Circulation: Heart } \\
\text { Failure, } 2016\end{array}$ & $\begin{array}{l}137 \mathrm{HFpEF} \\
\text { (subgroup from } \\
\text { RELAX trial) }\end{array}$ & $\begin{array}{l}\text { TAPSE; TAPSE/ } \\
\text { RVSP }\end{array}$ & $50 \%$ had TAPSE $<17 \mathrm{~mm}$ & No data on outcomes \\
\hline
\end{tabular}

CMR, cardiac magnetic resonance; FU, follow-up; HFpEF, heart failure with preserved ejection fraction; NT-proBNP, N-terminal pro-Btype natriuretic peptide; NYHA, New York Heart Association; PAH: pulmonary arterial hypertension; PH, pulmonary hypertension; REVEAL, registry to evaluate early and long-term PAH disease management; RVEDAI, right ventricular end-diastolic area index; RVEF, right ventricular ejection fraction; RVESAl: right ventricular end-systolic area index; RVESRI, right ventricular end-systolic remodeling index; RVESVi, right ventricular end-systolic volume index; RVFAC, right ventricular fractional area change; RVLS, right ventricular longitudinal strain; RVSP, right ventricular systolic pressure estimated by echocardiography; SSc-PAH, systemic sclerosis-related PAH; TAPSE, tricuspid annular plane systolic excursion.
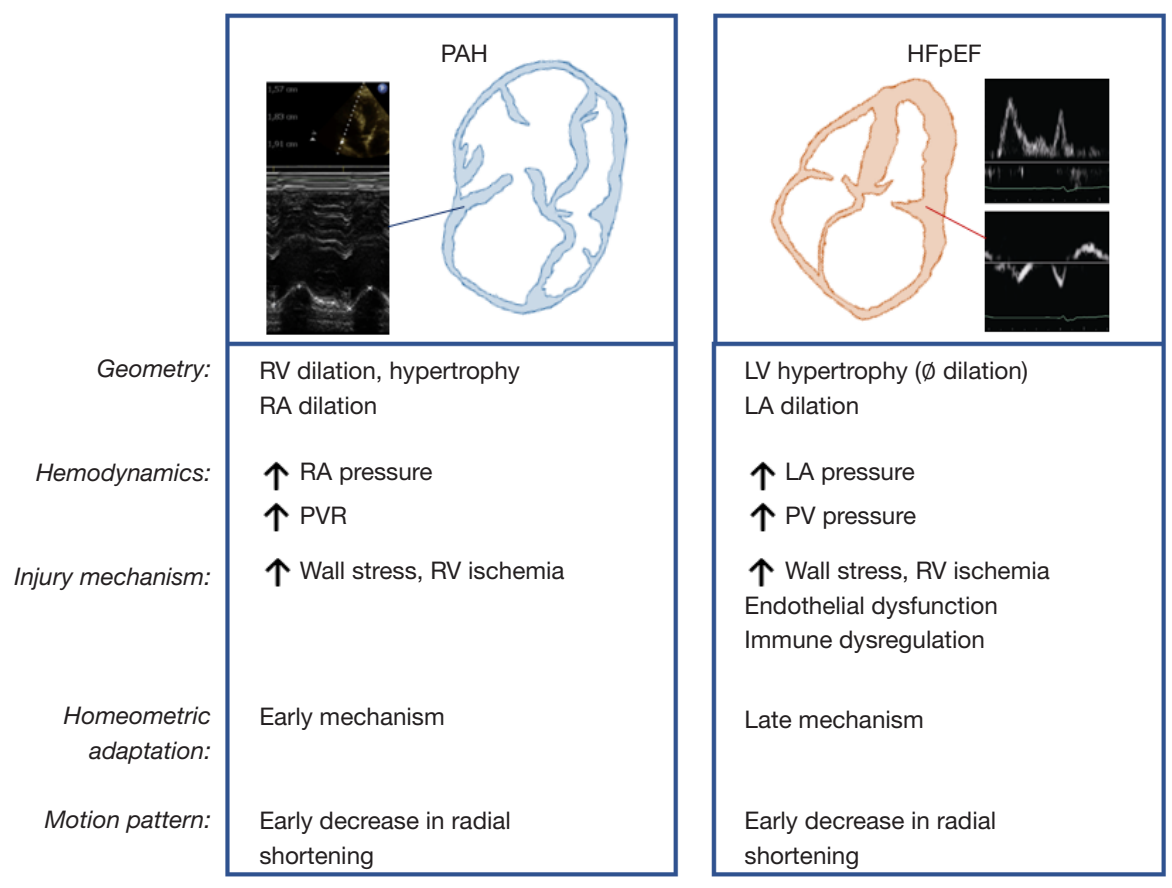

Figure 6 Schematic comparison of RV mechanics in PAH vs. HFpEF-PH. HFpEF, heart failure with preserved ejection fraction; LA, left atrial; LV, left ventricular; PAH, pulmonary arterial hypertension; PV, pulmonary vein; PVR, pulmonary vascular resistance; RA, right atrial; $\mathrm{RV}$, right ventricular.

interpretation of the Doppler signal (142).

The addition of right heart echocardiographic metrics (such as the RV/LV basal diameter ratio, LV eccentricity index, right atrial size) to the TR maximal velocity offers additional information to assess the level of probability of
PH based on echocardiography $(16,143)$. In patients with interpretable tricuspid signals, the area under the curve of the estimated RV systolic pressure for prediction of mPAP $\geq 25 \mathrm{mmHg}$ is high [0.97, 95\% CI (0.93-0.99), $\mathrm{P}<0.001]$. However, a significant proportion of subjects $(20 \%$ of 
healthy individuals and up to $40 \%$ of patients with $\mathrm{PAH}$ ) do not have an interpretable Doppler TR signal. In that case, the presence of right heart enlargement or dysfunction can indicate $\mathrm{PH}$ [with an area under the curve of 0.77 , 95\% CI (0.69-0.84), $\mathrm{P}<0.001]$ (142). Other markers of early remodeling of the right ventricle (such as $\mathrm{RV}$ apical sphericity) are currently being investigated for the early detection of $\mathrm{PH}$ in symptomatic patients.

Certain $\mathrm{RV}$ features are unique in patients with HFpEF-PH. Impaired RV transverse (radial) motion has been proposed as a potential screening parameter for $\mathrm{PH}$ in patients with HFpEF (39). In addition, by observing that patients with HFpEF-PH had smaller RV end-diastolic areas than patients with HFpEF without $\mathrm{PH}$, an echocardiographic-based score has been described (relying on left atrial area, LV mass index, $\mathrm{RV}$ end-diastolic area, in addition to history of diabetes mellitus and presence of atrial fibrillation) predicting the probability of HFpEF-PH with an area under the curve of $0.93,95 \%$ CI (0.92-0.94) (144).

\section{$R V$ metrics for prediction of outcomes in PAH vs. HFpEF}

Many studies have reported the prognostic value of RV systolic dysfunction (based on altered RVEF, RVLS, TAPSE or RVFAC) or RV adverse remodeling (based on increased $\mathrm{RV}$ end-systolic size or remodeling index) to predict outcomes in PAH (Table 1) $(31,32,145-148)$. A study showed that RVESRI (length of the RV free-wall in end-systole divided by the septal length) was a stronger predictor of 5 -year clinical worsening, in association with functional class and natriuretic peptide levels, and more reproducible than RVLS (32). Furthermore, RVESRI was additionally incremental to the validated Registry to Evaluate Early and Long-term PAH Disease Management (REVEAL) score for risk prediction of clinical worsening. A large CMR study on 576 patients with PAH confirmed that RV ESV indexed to body surface area was the strongest predictor of death, independently of the relative area change of the pulmonary artery (148). See the review of Sanders et al. on RV dysfunction and risk of death within this special issue (149).

In HFpEF, several studies have reported the prognostic value of different RV functional metrics $(8,132,133,150-152)$, such as TAPSE, RVFAC or RVLS by 2D echocardiography, or RVEF by CMR (Figure 2). $\mathrm{RV}$ dysfunction has been associated with mortality independent of the level of sPAP (10), which highlights the potential prognostic contribution of frequently associated comorbidities (such as coronary artery disease, hypertension, diabetes, sleep apnea or atrial fibrillation) of patients with HFpEF.

Fewer studies have correlated ventriculo-arterial coupling metrics and clinical outcomes in patients with PAH or HFpEF (Table 2). A coupling ratio Ees/Ea $<0.70$ (multibeat method) was associated with a higher incidence of clinical events (death, transplant or clinical failure) in patients with PAH (79). These findings were corroborated in a cohort of PAH patients with preserved RVEF, where Ees/Ea $<0.65$ (multibeat method) was an independent predictor of clinical worsening (153). The Ees/Ea ratio (single beat method) was reported to be lower in patients with HFpEF and combined pre- and post-capillary $\mathrm{PH}$, as compared to $\mathrm{HFpEF}$ and isolated post-capillary $\mathrm{PH}(1.17 \pm 0.27$ vs. $1.45 \pm 0.29, \mathrm{P}<0.05)(17)$. A SV/ESV ratio $\geq 0.515$ (volumetric method) was independently associated with survival in 50 individuals with different subtypes of $\mathrm{PH}$ (including Groups 1 and 2 $\mathrm{PH})$ (76). These findings were later corroborated in a study of 84 patients with $\mathrm{PAH}$, where a SV/ESV ratio $>0.534$ was associated with increased transplant-free survival (154). However, in neither of these two studies an association with survival was noticed when using the single beat method.

RV diastolic dysfunction has been shown to be associated with clinical outcomes in patients with PAH (Table 2). Increased Eed was associated with increased mortality [univariate hazard ratio $2.24,95 \%$ CI (1.05-4.80), P=0.037], and a cut-off $>0.53$ was proposed as predictive of survival (105). The diastolic coefficient $\beta$ is increased in patients with PAH $(0.050 \pm 0.005$ vs. $0.029 \pm 0.003$ in controls, $\mathrm{P}=0.034)$ and correlated with disease severity (104). Both Eed and $\beta$ decreased after therapy with parenteral treprostinil in treatment-naive patients with severe PAH (75).

\section{Future perspectives in the field of $\mathrm{RV}$ mechanics}

$\mathrm{RV}$ mechanics will continue to be an area of intensive research and clinical interest. The differences in patterns of motion and ventricular adaptation have to be further delineated based on the different phenotypes of patients with RV dysfunction. Newer imaging modalities such as 4D flow and vortex analysis, as well as computational modeling of $\mathrm{RV}$ contraction and flow offer a unique assessment of RV function $(155,156)$. Computational and integrative methods will contribute to deeper phenotyping of RV dysfunction 
Table 2 Selected studies assessing the prognostic value of metrics of ventriculo-arterial coupling or diastology in PAH and $\mathrm{HFpEF}$

\begin{tabular}{|c|c|c|c|c|}
\hline $\begin{array}{l}\text { First author, journal, } \\
\text { year }\end{array}$ & Number & RV metric & Study design & Link with outcomes \\
\hline \multicolumn{5}{|c|}{ Pulmonary arterial hypertension } \\
\hline $\begin{array}{l}\text { Vanderpool et al. } \\
\text { Eur Respir J, } 2017\end{array}$ & $33 \mathrm{PAH}$ & $\begin{array}{l}\text { Ees/Ea (single beat } \\
\text { method); SV/ ESV } \\
\text { (volumetric method) }\end{array}$ & $\begin{array}{l}\text { Treatment-naïve patients with } \\
\text { advanced PAH. Follow-up data } \\
\text { after treatment with parenteral } \\
\text { treprostinil }\end{array}$ & $\begin{array}{l}\text { SV/ESV increased after therapy with } \\
\text { parenteral treprostinil. No changes in } \\
\text { Ees/Ea by the single beat method }\end{array}$ \\
\hline $\begin{array}{l}\text { Richter et al. } \\
\text { AJRCCM, } 2020\end{array}$ & 38 pre-capillary $\mathrm{PH}$ & $\begin{array}{l}\text { Ees/Ea (multibeat } \\
\text { method) }\end{array}$ & Prospective & $\begin{array}{l}\text { Ees/Ea } \geq 0.70 \text { was associated with a } \\
\text { lower incidence of clinical worsening }\end{array}$ \\
\hline $\begin{array}{l}\text { Hsu et al. J Am } \\
\text { Heart Assoc, } 2020\end{array}$ & $26 \mathrm{PAH}$ & $\begin{array}{l}\text { Ees/Ea (multibeat } \\
\text { method) }\end{array}$ & Retrospective & $\begin{array}{l}\text { Ees/Ea }>0.65 \text { was associated with a } \\
\text { lower incidence of clinical worsening. } \\
\text { Ees/Ea }>0.65 \text { remained predictive of } \\
\text { outcomes in the multivariate regression } \\
\text { model }\end{array}$ \\
\hline \multicolumn{5}{|c|}{ Heart failure with preserved ejection fraction } \\
\hline $\begin{array}{l}\text { Gorter el al. Eur } \\
\text { Heart J Cardiovasc } \\
\text { Imaging, } 2018\end{array}$ & $\begin{array}{l}102 \text { HFpEF (76 with } \\
\text { HFpEF-PH) }\end{array}$ & TAPSE/sPAP & Prospective & $\begin{array}{l}\text { TAPSE/sPAP }<0.36 \text { was associated } \\
\text { with increased all-cause mortality }\end{array}$ \\
\hline \multicolumn{5}{|l|}{ Diastology } \\
\hline $\begin{array}{l}\text { Trip et al. Eur } \\
\text { Respir J, } 2015\end{array}$ & $63 \mathrm{PAH}$ & $\begin{array}{l}\text { Eed (single beat } \\
\text { method) }\end{array}$ & Retrospective & $\begin{array}{l}\text { Univariate hazard ratio for Eed was } \\
2.24[95 \% \mathrm{Cl}(1.05-4.80), \mathrm{P}=0.037] \text {. } \\
\text { Eed }>0.53 \text { predictive of survival }\end{array}$ \\
\hline $\begin{array}{l}\text { Vanderpool et al. } \\
\text { Eur Respir J, } 2017\end{array}$ & $33 \mathrm{PAH}$ & $\begin{array}{l}\text { Eed (single beat } \\
\text { method); } \beta \text { (single } \\
\text { beat method) }\end{array}$ & $\begin{array}{l}\text { Treatment-naïve patients with } \\
\text { advanced PAH. Follow-up data } \\
\text { after treatment with parenteral } \\
\text { treprostinil }\end{array}$ & $\begin{array}{l}\text { Therapy with parenteral treprostinil was } \\
\text { associated with significant reductions } \\
\text { in both Eed and } \beta\end{array}$ \\
\hline
\end{tabular}

$\beta$, diastolic coefficient $\beta$; Ea, arterial elastance; Eed, end-diastolic elastance; Ees, end-systolic elastance; ESV, end-systolic volume; $\mathrm{HFpEF}$, heart failure with preserved ejection fraction; $\mathrm{PAH}$, pulmonary arterial hypertension; $\mathrm{PH}$, pulmonary hypertension; sPAP, systolic pulmonary artery pressure; SV, stroke volume; TAPSE, tricuspid annular plane systolic excursion. 
and contribute to automation of image analysis. Finally, artificial intelligence, knowledge acquisition and machinelearning algorithms using clinical and cardiac imaging data are expected to add value in the process of proper $\mathrm{RV}$ phenotyping, as well as its association with clinical outcomes $(157,158)$.

\section{Conclusions}

$\mathrm{RV}$ dysfunction is an independent determinant on survival in patients with all forms of PH. An understanding of RV mechanics allows us to not only understand the change in contraction and cardiac filling but also its load-independent determinants, energetics and flow dynamics. Computational approaches will enable in the future an integrated analysis of RV mechanics for clinical practice, therapeutics and research.

\section{Acknowledgments}

Funding: None.

\section{Footnote}

Provenance and Peer Review: This article was commissioned by the Guest Editors (Martin Koestenberger, HarmJan Bogaard and Georg Hansmann) for the series "Right Ventricular Dysfunction" published in Cardiovascular Diagnosis and Therapy. The article was sent for external peer review organized by the Editor-in-Chief and the editorial office.

Conflicts of Interest: All authors have completed the ICMJE uniform disclosure form (available at http://dx.doi. org/10.21037/cdt-20-479). The series "Right Ventricular Dysfunction" was commissioned by the editorial office without any funding or sponsorship. GH served as the unpaid Guest Editor of the series. GH reports grants from German Research Foundation (DFG; HA4348/2-2 and HA4348/6-2 KFO311), from Federal Ministry of Education and Research (BMBF ViP+ program-03VP08053; BMBF 01KC2001B), from European Pediatric Pulmonary Vascular Disease Network (www.pvdnetwork.org), outside the submitted work. AYD reports grants from Edwards (2019) research (equipment grant), outside the submitted work; and Speaker bureau and KOL for CAE Healthcare and Masimo. Dr. FSdM reports grants from The Netherlands CardioVascular Research Initiative: the Dutch Heart Foun- dation, Dutch Federation of University Medical Centres, the Netherlands Organisation for Health Research and Development, and the Royal Netherlands Academy of Sciences (CVON-2012-08 PHAEDRA, CVON-2018-29 PHAEDRA-IMPACT, CVON-2017-10 Dolphin-Genesis ), from The Netherlands Organization for Scientific Research (NWO-VIDI: 917.18.338), from The Dutch Heart Foundation Dekker senior post-doc grant (2018T059), outside the submitted work. The authors have no other conflicts of interest to declare.

Ethical Statement: The authors are accountable for all aspects of the work in ensuring that questions related to the accuracy or integrity of any part of the work are appropriately investigated and resolved.

Open Access Statement: This is an Open Access article distributed in accordance with the Creative Commons Attribution-NonCommercial-NoDerivs 4.0 International License (CC BY-NC-ND 4.0), which permits the noncommercial replication and distribution of the article with the strict proviso that no changes or edits are made and the original work is properly cited (including links to both the formal publication through the relevant DOI and the license). See: https://creativecommons.org/licenses/by-nc-nd/4.0/.

\section{References}

1. Champion HC, Michelakis ED, Hassoun PM. Comprehensive invasive and noninvasive approach to the right ventricle-pulmonary circulation unit: state of the art and clinical and research implications. Circulation 2009;120:992-1007.

2. Vanderpool RR, Saul M, Nouraie M, et al. Association Between Hemodynamic Markers of Pulmonary Hypertension and Outcomes in Heart Failure With Preserved Ejection Fraction. JAMA Cardiol 2018;3:298-306.

3. Vonk Noordegraaf A, Chin KM, Haddad F, et al. Pathophysiology of the right ventricle and of the pulmonary circulation in pulmonary hypertension: an update. Eur Respir J 2019;53:1801900.

4. Hoeper MM, Humbert M, Souza R, et al. A global view of pulmonary hypertension. Lancet Respir Med 2016;4:306-22.

5. Rich S, Pogoriler J, Husain AN, et al. Long-term effects of epoprostenol on the pulmonary vasculature in idiopathic pulmonary arterial hypertension. Chest 2010;138:1234-9. 
6. Ghio S, Gavazzi A, Campana C, et al. Independent and additive prognostic value of right ventricular systolic function and pulmonary artery pressure in patients with chronic heart failure. J Am Coll Cardiol 2001;37:183-8.

7. Gerges C, Gerges M, Lang MB, et al. Diastolic pulmonary vascular pressure gradient: a predictor of prognosis in "out-of-proportion" pulmonary hypertension. Chest 2013;143:758-66.

8. Mohammed SF, Hussain I, AbouEzzeddine OF, et al. Right ventricular function in heart failure with preserved ejection fraction: a community-based study. Circulation 2014;130:2310-20.

9. Zakeri R, Mohammed SF. Epidemiology of Right Ventricular Dysfunction in Heart Failure with Preserved Ejection Fraction. Curr Heart Fail Rep 2015;12:295-301.

10. Raina A, Meeran T. Right Ventricular Dysfunction and Its Contribution to Morbidity and Mortality in Left Ventricular Heart Failure. Curr Heart Fail Rep 2018;15:94-105.

11. Pfeffer MA, Shah AM, Borlaug BA. Heart Failure With Preserved Ejection Fraction In Perspective. Circ Res 2019;124:1598-617.

12. Pieske B, Tschope C, de Boer RA, et al. How to diagnose heart failure with preserved ejection fraction: the HFAPEFF diagnostic algorithm: a consensus recommendation from the Heart Failure Association (HFA) of the European Society of Cardiology (ESC). Eur Heart J 2019;40:3297-317.

13. Paulus WJ, Tschope C. A novel paradigm for heart failure with preserved ejection fraction: comorbidities drive myocardial dysfunction and remodeling through coronary microvascular endothelial inflammation. J Am Coll Cardiol 2013;62:263-71.

14. Reddy YNV, Carter RE, Obokata M, et al. A Simple, Evidence-Based Approach to Help Guide Diagnosis of Heart Failure With Preserved Ejection Fraction. Circulation 2018;138:861-70.

15. Fayyaz AU, Edwards WD, Maleszewski JJ, et al. Global Pulmonary Vascular Remodeling in Pulmonary Hypertension Associated With Heart Failure and Preserved or Reduced Ejection Fraction. Circulation 2018;137:1796-810.

16. Galiè N, Humbert M, Vachiery JL, et al. 2015 ESC/ERS Guidelines for the diagnosis and treatment of pulmonary hypertension: The Joint Task Force for the Diagnosis and Treatment of Pulmonary Hypertension of the European Society of Cardiology (ESC) and the European Respiratory Society (ERS): Endorsed by: Association for
European Paediatric and Congenital Cardiology (AEPC), International Society for Heart and Lung Transplantation (ISHLT). Eur Respir J 2015;46:903-75.

17. Gerges M, Gerges C, Pistritto AM, et al. Pulmonary Hypertension in Heart Failure. Epidemiology, Right Ventricular Function, and Survival. Am J Respir Crit Care Med 2015;192:1234-46.

18. Vachiéry JL, Tedford RJ, Rosenkranz S, et al. Pulmonary hypertension due to left heart disease. Eur Respir J 2019;53.

19. Lam CS, Roger VL, Rodeheffer RJ, et al. Pulmonary hypertension in heart failure with preserved ejection fraction: a community-based study. J Am Coll Cardiol 2009;53:1119-26.

20. Hoeper MM, Barbera JA, Channick RN, et al. Diagnosis, assessment, and treatment of non-pulmonary arterial hypertension pulmonary hypertension. J Am Coll Cardiol 2009;54:S85-96.

21. Vonk-Noordegraaf A, Haddad F, Chin KM, et al. Right heart adaptation to pulmonary arterial hypertension: physiology and pathobiology. J Am Coll Cardiol 2013;62:D22-33.

22. Gorter TM, Hoendermis ES, van Veldhuisen DJ, et al. Right ventricular dysfunction in heart failure with preserved ejection fraction: a systematic review and metaanalysis. Eur J Heart Fail 2016;18:1472-87.

23. Lahm T, Douglas IS, Archer SL, et al. Assessment of Right Ventricular Function in the Research Setting: Knowledge Gaps and Pathways Forward. An Official American Thoracic Society Research Statement. Am J Respir Crit Care Med 2018;198:e15-e43.

24. Bellofiore A, Chesler NC. Methods for measuring right ventricular function and hemodynamic coupling with the pulmonary vasculature. Ann Biomed Eng 2013;41:1384-98.

25. Wang Z, Chesler NC. Pulmonary vascular wall stiffness: An important contributor to the increased right ventricular afterload with pulmonary hypertension. Pulm Circ 2011;1:212-23.

26. von Anrep G. On local vascular reactions and their interpretation. J Physiol 1912;45:318-27.

27. Cingolani HE, Perez NG, Cingolani OH, et al. The Anrep effect: 100 years later. Am J Physiol Heart Circ Physiol 2013;304:H175-82.

28. Vonk Noordegraaf A, Westerhof BE, Westerhof N. The relationship between the right ventricle and its load in pulmonary hypertension. J Am Coll Cardiol 2017;69:236-43. 
29. Haddad F, Hunt SA, Rosenthal DN, et al. Right ventricular function in cardiovascular disease, part I: Anatomy, physiology, aging, and functional assessment of the right ventricle. Circulation 2008;117:1436-48.

30. Kovács A, Lakatos B, Tokodi M, et al. Right ventricular mechanical pattern in health and disease: beyond longitudinal shortening. Heart Fail Rev 2019;24:511-20.

31. Fine NM, Chen L, Bastiansen PM, et al. Outcome prediction by quantitative right ventricular function assessment in 575 subjects evaluated for pulmonary hypertension. Circ Cardiovasc Imaging 2013;6:711-21.

32. Amsallem M, Sweatt AJ, Aymami MC, et al. Right heart end-systolic remodeling index strongly predicts outcomes in pulmonary arterial hypertension: comparison with validated models. Circ Cardiovasc Imaging 2017;10:e005771.

33. Grønlykke L, Korshin A, Holmgaard F, et al. Severe loss of right ventricular longitudinal contraction occurs after cardiopulmonary bypass in patients with preserved right ventricular output. Int J Cardiovasc Imaging 2019;35:1661-70.

34. Singh A, Huang X, Dai L, et al. Right ventricular function is reduced during cardiac surgery independent of procedural characteristics, reoperative status, or pericardiotomy. J Thorac Cardiovasc Surg 2020;159:14301438.e4.

35. Tamborini G, Muratori M, Brusoni D, et al. Is right ventricular systolic function reduced after cardiac surgery? A two- and three-dimensional echocardiographic study. Eur J Echocardiogr 2009;10:630-4.

36. Navaratnam M, DiNardo J. Peri-operative right ventricular dysfunction - the anesthesiologist's view. Cardiovasc Diagn Ther 2020. (In Press).

37. Kind T, Mauritz GJ, Marcus JT, et al. Navaratnam M, DiNardo J. Peri-operative right ventricular dysfunctionthe anesthesiologist's view. Cardiovasc Diagn Ther 2020;10:1725-34.

38. Bosch L, Lam CSP, Gong L, et al. Right ventricular dysfunction in left-sided heart failure with preserved versus reduced ejection fraction. Eur J Heart Fail 2017;19:1664-71.

39. Gorter TM, van Veldhuisen DJ, Bauersachs J, et al. Right heart dysfunction and failure in heart failure with preserved ejection fraction: mechanisms and management. Position statement on behalf of the Heart Failure Association of the European Society of Cardiology. Eur J Heart Fail 2018;20:16-37.

40. Moceri P, Bouvier P, Baudouy D, et al. Cardiac remodelling amongst adults with various aetiologies of pulmonary arterial hypertension including Eisenmenger syndrome-implications on survival and the role of right ventricular transverse strain. Eur Heart J Cardiovasc Imaging 2017;18:1262-70.

41. Koestenberger M, Apitz C, Abdul-Khaliq H, et al. Transthoracic echocardiography for the evaluation of children and adolescents with suspected or confirmed pulmonary hypertension. Expert consensus statement on the diagnosis and treatment of paediatric pulmonary hypertension. The European Paediatric Pulmonary Vascular Disease Network, endorsed by ISHLT and D6PK. Heart 2016;102 Suppl 2:ii14-22.

42. Koestenberger M, Friedberg MK, Nestaas E, et al. Transthoracic echocardiography in the evaluation of pediatric pulmonary hypertension and ventricular dysfunction. Pulm Circ 2016;6:15-29.

43. Hansmann G, Koestenberger M, Alastalo TP, et al. 2019 updated consensus statement on the diagnosis and treatment of pediatric pulmonary hypertension: The European Pediatric Pulmonary Vascular Disease Network (EPPVDN), endorsed by AEPC, ESPR and ISHLT. J Heart Lung Transplant 2019;38:879-901.

44. Santens B, Van De Bruaene A, De Meester P, et al. Diagnosis and treatment of right ventricular dysfunction in congenital heart disease. Cardiovasc Diagn Ther 2020;10:1625-45.

45. Koestenberger M, Avian A, Chouvarine P, et al. Right ventricular end-systolic remodeling index in the assessment of pediatric pulmonary arterial hypertension. The European Pediatric Pulmonary Vascular Disease Network (EPPVDN). Pediatr Res 2020;88:285-92.

46. Di Maria MV, Campbell KR, Burkett DA, et al. Parameters of Right Ventricular Function Reveal Ventricular-Vascular Mismatch as Determined by Right Ventricular Stroke Work versus Pulmonary Vascular Resistance in Children with Pulmonary Hypertension. J Am Soc Echocardiogr 2020;33:218-25.

47. Mauritz GJ, Kind T, Marcus JT, et al. Progressive changes in right ventricular geometric shortening and longterm survival in pulmonary arterial hypertension. Chest 2012;141:935-43.

48. Haddad F, Guihaire J, Skhiri M, et al. Septal curvature is marker of hemodynamic, anatomical, and electromechanical ventricular interdependence in patients with pulmonary arterial hypertension. Echocardiography 2014;31:699-707.

49. Burkett DA, Patel SS, Mertens L, et al. Relationship 
Between Left Ventricular Geometry and Invasive Hemodynamics in Pediatric Pulmonary Hypertension. Circ Cardiovasc Imaging 2020;13:e009825.

50. Koestenberger M, Hansmann G. Left ventricular geometry and near-simultaneous invasive hemodynamics in pediatric pulmonary hypertension. Circ Cardiovasc Imaging 2020;13:e010787.

51. Burkett DA, Slorach C, Patel SS, et al. Left ventricular myocardial function in children with pulmonary hypertension: relation to right ventricular performance and hemodynamics. Circ Cardiovasc Imaging 2015;8:10.

52. Badagliacca R, Poscia R, Pezzuto B, et al. Right ventricular dyssynchrony in idiopathic pulmonary arterial hypertension: determinants and impact on pump function. J Heart Lung Transplant 2015;34:381-9.

53. Mauritz GJ, Vonk-Noordegraaf A, Kind T, et al. Pulmonary endarterectomy normalizes interventricular dyssynchrony and right ventricular systolic wall stress. J Cardiovasc Magn Reson 2012;14:5.

54. Attard MI, Dawes TJW, de Marvao A, et al. Metabolic pathways associated with right ventricular adaptation to pulmonary hypertension: 3D analysis of cardiac magnetic resonance imaging. Eur Heart J Cardiovasc Imaging 2019;20:668-76.

55. Naeije R. Assessment of right ventricular function in pulmonary hypertension. Curr Hypertens Rep 2015;17:35.

56. Guihaire J, Haddad F, Boulate D, et al. Non-invasive indices of right ventricular function are markers of ventricular-arterial coupling rather than ventricular contractility: insights from a porcine model of chronic pressure overload. Eur Heart J Cardiovasc Imaging 2013;14:1140-9.

57. Truong U, Meinel K, Haddad F, et al. Update on noninvasive imaging of right ventricle dysfunction in pulmonary hypertension. Cardiovasc Diagn Ther 2020. [Epub ahead of print].

58. Tello K, Seeger W, Naeije R, et al. Right heart failure in pulmonary hypertension: Diagnosis and new perspectives on vascular and direct right ventricular treatment. Br J Pharmacol 2019. [Epub ahead of print].

59. Dell'Italia LJ, Walsh RA. Application of a time varying elastance model to right ventricular performance in man. Cardiovasc Res 1988;22:864-74.

60. Maughan WL, Shoukas AA, Sagawa K, et al. Instantaneous pressure-volume relationship of the canine right ventricle. Circ Res 1979;44:309-15.

61. Tedford RJ. Determinants of right ventricular afterload (2013 Grover Conference series). Pulm Circ 2014;4:211-9.
62. Boulate D, Mercier O, Guihaire J, et al. Pulmonary Circulatory - Right Ventricular Uncoupling: New Insights Into Pulmonary Hypertension Pathophysiology. Pulmonary Hypertension. Cham: Springer International Publishing, 2016:241-53.

63. Tedford RJ, Mudd JO, Girgis RE, et al. Right ventricular dysfunction in systemic sclerosis-associated pulmonary arterial hypertension. Circ Heart Fail 2013;6:953-63.

64. Hsu S, Houston BA, Tampakakis E, et al. Right Ventricular Functional Reserve in Pulmonary Arterial Hypertension. Circulation 2016;133:2413-22.

65. Tello K, Richter MJ, Axmann J, et al. More on SingleBeat Estimation of Right Ventriculoarterial Coupling in Pulmonary Arterial Hypertension. Am J Respir Crit Care Med 2018;198:816-8.

66. Tello K, Dalmer A, Husain-Syed F, et al. Multibeat Right Ventricular-Arterial Coupling during a Positive Acute Vasoreactivity Test. Am J Respir Crit Care Med 2019;199:e41-e42.

67. Brimioulle S, Wauthy P, Ewalenko P, et al. Single-beat estimation of right ventricular end-systolic pressurevolume relationship. Am J Physiol Heart Circ Physiol 2003;284:H1625-30.

68. Westerhof N, Stergiopulos N, Noble MIM, et al. Cardiac Power and Ventriculo-Arterial Coupling. Snapshots of Hemodynamics. Springer International Publishing, 2019:135-42.

69. Philip JL, Chesler NC. Know your limitations: assumptions in the single-beat method for estimating right ventricular-pulmonary vascular coupling. Am J Respir Crit Care Med 2018;198:707-9.

70. Bellofiore A, Vanderpool R, Brewis MJ, et al. A novel single-beat approach to assess right ventricular systolic function. J Appl Physiol (1985) 2018;124:283-90.

71. Vanderpool RR, Puri R, Osorio A, et al. EXPRESS: Surfing the Right Ventricular Pressure Waveform: Methods to assess Global, Systolic and Diastolic RV Function from a Clinical Right Heart Catheterization. Pulm Circ 2019;10:2045894019850993.

72. Dell'Italia LJ. Anatomy and physiology of the right ventricle. Cardiol Clin 2012;30:167-87.

73. Kono A, Maughan WL, Sunagawa K, et al. The use of left ventricular end-ejection pressure and peak pressure in the estimation of the end-systolic pressure-volume relationship. Circulation 1984;70:1057-65.

74. Starling MR, Walsh RA, Dell'Italia LJ, et al. The relationship of various measures of end-systole to left ventricular maximum time-varying elastance in man. 
Circulation 1987;76:32-43.

75. Vanderpool RR, Desai AA, Knapp SM, et al. How prostacyclin therapy improves right ventricular function in pulmonary arterial hypertension. Eur Respir J 2017;50:1700764.

76. Vanderpool RR, Pinsky MR, Naeije R, et al. RVpulmonary arterial coupling predicts outcome in patients referred for pulmonary hypertension. Heart 2015;101:37-43.

77. Alyono D, Larson VE, Anderson RW. Defining end systole for end-systolic pressure-volume ratio. J Surg Res 1985;39:344-50.

78. Breeman KTN, Dufva M, Ploegstra MJ, et al. Right ventricular-vascular coupling ratio in pediatric pulmonary arterial hypertension: A comparison between cardiac magnetic resonance and right heart catheterization measurements. Int J Cardiol 2019;293:211-7.

79. Richter MJ, Peters D, Ghofrani HA, et al. Evaluation and Prognostic Relevance of Right Ventricular-Arterial Coupling in Pulmonary Hypertension. Am J Respir Crit Care Med 2020;201:116-9.

80. Sanz J, Garcia-Alvarez A, Fernandez-Friera L, et al. Right ventriculo-arterial coupling in pulmonary hypertension: a magnetic resonance study. Heart 2012;98:238-43.

81. Vanderpool RR, Rischard F, Naeije R, et al. Simple functional imaging of the right ventricle in pulmonary hypertension: Can right ventricular ejection fraction be improved? Int J Cardiol 2016;223:93-4.

82. Trip P, Kind T, van de Veerdonk MC, et al. Accurate assessment of load-independent right ventricular systolic function in patients with pulmonary hypertension. J Heart Lung Transplant 2013;32:50-5.

83. Guazzi M, Bandera F, Pelissero G, et al. Tricuspid annular plane systolic excursion and pulmonary arterial systolic pressure relationship in heart failure: an index of right ventricular contractile function and prognosis. Am J Physiol Heart Circ Physiol 2013;305:H1373-81.

84. Tello K, Wan J, Dalmer A, et al. Validation of the Tricuspid Annular Plane Systolic Excursion/Systolic Pulmonary Artery Pressure Ratio for the Assessment of Right Ventricular-Arterial Coupling in Severe Pulmonary Hypertension. Circ Cardiovasc Imaging 2019;12:e009047.

85. Kang G, Ha R, Banerjee D. Pulmonary artery pulsatility index predicts right ventricular failure after left ventricular assist device implantation. J Heart Lung Transplant 2016;35:67-73.

86. Kochav SM, Flores RJ, Truby LK, et al. Prognostic Impact of Pulmonary Artery Pulsatility Index (PAPi) in Patients
With Advanced Heart Failure: Insights From the ESCAPE Trial. J Card Fail 2018;24:453-9.

87. Stevens GR, Garcia-Alvarez A, Sahni S, et al. RV dysfunction in pulmonary hypertension is independently related to pulmonary artery stiffness. JACC Cardiovasc Imaging 2012;5:378-87.

88. Amsallem M, Boulate D, Aymami M, et al. Load Adaptability in Patients With Pulmonary Arterial Hypertension. Am J Cardiol 2017;120:874-82.

89. French S, Amsallem M, Ouazani N, et al. Non-invasive right ventricular load adaptability indices in patients with scleroderma-associated pulmonary arterial hypertension. Pulm Circ 2018;8:2045894018788268.

90. Maksuti E, Carlsson M, Arheden H, et al. Hydraulic forces contribute to left ventricular diastolic filling. Sci Rep 2017;7:43505.

91. Nagueh SF, Smiseth OA, Appleton CP, et al. Recommendations for the Evaluation of Left Ventricular Diastolic Function by Echocardiography: An Update from the American Society of Echocardiography and the European Association of Cardiovascular Imaging. J Am Soc Echocardiogr 2016;29:277-314.

92. Leeuwenburgh BP, Steendijk P, Helbing WA, et al. Indexes of diastolic RV function: load dependence and changes after chronic RV pressure overload in lambs. Am J Physiol Heart Circ Physiol 2002;282:H1350-8.

93. Schwarz ER, Dashti R. The clinical quandary of left and right ventricular diastolic dysfunction and diastolic heart failure. Cardiovasc J Afr 2010;21:212-20.

94. Rudski LG, Lai WW, Afilalo J, et al. Guidelines for the echocardiographic assessment of the right heart in adults: a report from the American Society of Echocardiography endorsed by the European Association of Echocardiography, a registered branch of the European Society of Cardiology, and the Canadian Society of Echocardiography. J Am Soc Echocardiogr 2010;23:685713; quiz 86-8.

95. Tang WH, Kitai T. Intrarenal venous flow: a window into the congestive kidney failure phenotype of heart failure? JACC Heart Fail 2016;4:683-6.

96. Chakko S, de Marchena E, Kessler KM, et al. Right ventricular diastolic function in systemic hypertension. Am J Cardiol 1990;65:1117-20.

97. Yu CM, Sanderson JE, Chan S, et al. Right ventricular diastolic dysfunction in heart failure. Circulation 1996;93:1509-14.

98. Dambrauskaite V, Delcroix M, Claus P, et al. The evaluation of pulmonary hypertension using right 
ventricular myocardial isovolumic relaxation time. J Am Soc Echocardiogr 2005;18:1113-20.

99. Bréchot N, Gambotti L, Lafitte S, et al. Usefulness of right ventricular isovolumic relaxation time in predicting systolic pulmonary artery pressure. Eur J Echocardiogr 2008;9:547-54.

100.Amsallem M, Boulate D, Kooreman Z, et al. Investigating the value of right heart echocardiographic metrics for detection of pulmonary hypertension in patients with advanced lung disease. Int J Cardiovasc Imaging 2017;33:825-35.

101. Weiss JL, Frederiksen JW, Weisfeldt ML. Hemodynamic determinants of the time-course of fall in canine left ventricular pressure. J Clin Invest 1976;58:751-60.

102. Murch SD, La Gerche A, Roberts TJ, et al. Abnormal right ventricular relaxation in pulmonary hypertension. Pulm Circ 2015;5:370-5.

103.Prins KW, Rose L, Archer SL, et al. Clinical Determinants and Prognostic Implications of Right Ventricular Dysfunction in Pulmonary Hypertension Caused by Chronic Lung Disease. J Am Heart Assoc 2019;8:e011464.

104. Rain S, Handoko ML, Trip P, et al. Right ventricular diastolic impairment in patients with pulmonary arterial hypertension. Circulation 2013;128:2016-25, 1-10.

105. Trip P, Rain S, Handoko ML, et al. Clinical relevance of right ventricular diastolic stiffness in pulmonary hypertension. Eur Respir J 2015;45:1603-12.

106. Fredriksson AG, Zajac J, Eriksson J, et al. 4-D blood flow in the human right ventricle. Am J Physiol Heart Circ Physiol 2011;301:H2344-50.

107. Barker N, Fidock B, Johns CS, et al. A Systematic Review of Right Ventricular Diastolic Assessment by 4D Flow CMR. Biomed Res Int 2019;2019:6074984.

108. Dyverfeldt P, Bissell M, Barker AJ, et al. 4D flow cardiovascular magnetic resonance consensus statement. J Cardiovasc Magn Reson 2015;17:72.

109. Fenster BE, Browning J, Schroeder JD, et al. Vorticity is a marker of right ventricular diastolic dysfunction. Am J Physiol Heart Circ Physiol 2015;309:H1087-93.

110. Browning JR, Hertzberg JR, Schroeder JD, et al. 4D flow assessment of vorticity in right ventricular diastolic dysfunction. Bioengineering (Basel) 2017;4:30.

111. Fredriksson AG, Svalbring E, Eriksson J, et al. 4D flow MRI can detect subtle right ventricular dysfunction in primary left ventricular disease. J Magn Reson Imaging 2016;43:558-65.

112.Burkhoff D, Sagawa K. Ventricular efficiency predicted by an analytical model. Am J Physiol 1986;250:R1021-7.
113. Saouti N, Westerhof N, Helderman F, et al. Right ventricular oscillatory power is a constant fraction of total power irrespective of pulmonary artery pressure. Am J Respir Crit Care Med 2010;182:1315-20.

114. Bing RJ, Hammond MM, et al. The measurement of coronary blood flow, oxygen consumption, and efficiency of the left ventricle in man. Am Heart J 1949;38:1-24.

115. Knaapen P, Germans T, Knuuti J, et al. Myocardial energetics and efficiency: current status of the noninvasive approach. Circulation 2007;115:918-27.

116. Wong YY, Ruiter G, Lubberink M, et al. Right ventricular failure in idiopathic pulmonary arterial hypertension is associated with inefficient myocardial oxygen utilization. Circ Heart Fail 2011;4:700-6.

117. Braunwald E. Control of myocardial oxygen consumption: physiologic and clinical considerations. Am J Cardiol 1971;27:416-32.

118.van Wolferen SA, Marcus JT, Westerhof N, et al. Right coronary artery flow impairment in patients with pulmonary hypertension. Eur Heart J 2008;29:120-7.

119. Piao L, Fang YH, Parikh K, et al. Cardiac glutaminolysis: a maladaptive cancer metabolism pathway in the right ventricle in pulmonary hypertension. J Mol Med (Berl) 2013;91:1185-97.

120.Legchenko E, Chouvarine P, Borchert P, et al. PPARgamma agonist pioglitazone reverses pulmonary hypertension and prevents right heart failure via fatty acid oxidation. Sci Transl Med 2018;10:eaao0303.

121. Fitzpatrick JM, Grant BJ. Effects of pulmonary vascular obstruction on right ventricular afterload. Am Rev Respir Dis 1990;141:944-52.

122.Suga H. Ventricular energetics. Physiol Rev 1990;70:247-77.

123. Armbrecht JJ, Buxton DB, Schelbert HR. Validation of [1-11C]acetate as a tracer for noninvasive assessment of oxidative metabolism with positron emission tomography in normal, ischemic, postischemic, and hyperemic canine myocardium. Circulation 1990;81:1594-605.

124. Sunagawa K, Maughan WL, Sagawa K. Optimal arterial resistance for the maximal stroke work studied in isolated canine left ventricle. Circ Res 1985;56:586-95.

125. Ryan JJ, Archer SL. The right ventricle in pulmonary arterial hypertension: disorders of metabolism, angiogenesis and adrenergic signaling in right ventricular failure. Circ Res 2014;115:176-88.

126. Culley MK, Chan SY. Mitochondrial metabolism in pulmonary hypertension: beyond mountains there are mountains. J Clin Invest 2018;128:3704-15. 
127. Brittain EL, Talati M, Fessel JP, et al. Fatty Acid Metabolic Defects and Right Ventricular Lipotoxicity in Human Pulmonary Arterial Hypertension. Circulation 2016;133:1936-44.

128. Hemnes AR, Luther JM, Rhodes CJ, et al. Human PAH is characterized by a pattern of lipid-related insulin resistance. JCI Insight 2019;4:e123611.

129. Wang L, Zhang Y, Yan C, et al. Evaluation of right ventricular volume and ejection fraction by gated (18) F-FDG PET in patients with pulmonary hypertension: comparison with cardiac MRI and CT. J Nucl Cardiol 2013;20:242-52.

130. Agrawal V, Lahm T, Hansmann G, et al. Molecular mechanisms of right ventricular dysfunction in pulmonary arterial hypertension: focus on the coronary vasculature, sex hormones, and glucose/lipid metabolism. Cardiovasc Diagn Ther 2020;10:1522-40.

131. Thenappan T, Shah SJ, Gomberg-Maitland M, et al. Clinical characteristics of pulmonary hypertension in patients with heart failure and preserved ejection fraction. Circ Heart Fail 2011;4:257-65.

132. Melenovsky V, Hwang SJ, Lin G, et al. Right heart dysfunction in heart failure with preserved ejection fraction. Eur Heart J 2014;35:3452-62.

133. Aschauer S, Kammerlander AA, Zotter-Tufaro C, et al. The right heart in heart failure with preserved ejection fraction: insights from cardiac magnetic resonance imaging and invasive haemodynamics. Eur J Heart Fail 2016;18:71-80.

134. Nickel NP, Yuan K, Dorfmuller P, et al. Beyond the Lungs: Systemic Manifestations of Pulmonary Arterial Hypertension. Am J Respir Crit Care Med 2020;201:148-57.

135. Rabinovitch M, Guignabert C, Humbert M, et al. Inflammation and immunity in the pathogenesis of pulmonary arterial hypertension. Circ Res 2014;115:165-75.

136. Tolle J, Waxman A, Systrom D. Impaired systemic oxygen extraction at maximum exercise in pulmonary hypertension. Med Sci Sports Exerc 2008;40:3-8.

137. Dhakal BP, Malhotra R, Murphy RM, et al. Mechanisms of exercise intolerance in heart failure with preserved ejection fraction: the role of abnormal peripheral oxygen extraction. Circ Heart Fail 2015;8:286-94.

138. Panagiotou M, Vogiatzis I, Louvaris Z, et al. Near infrared spectroscopy for the assessment of peripheral tissue oxygenation in pulmonary arterial hypertension. Eur Respir J 2016;48:1224-7.

139.Hearon CM, Jr., Sarma S, Dias KA, et al. Impaired oxygen uptake kinetics in heart failure with preserved ejection fraction. Heart 2019;105:1552-8.

140. Opotowsky AR, Ojeda J, Rogers F, et al. A simple echocardiographic prediction rule for hemodynamics in pulmonary hypertension. Circ Cardiovasc Imaging 2012;5:765-75.

141. D'Alto M, Romeo E, Argiento P, et al. Echocardiographic prediction of pre- versus postcapillary pulmonary hypertension. J Am Soc Echocardiogr 2015;28:108-15.

142.Amsallem M, Sternbach JM, Adigopula S, et al. Addressing the Controversy of Estimating Pulmonary Arterial Pressure by Echocardiography. J Am Soc Echocardiogr 2016;29:93-102.

143. Frost A, Badesch D, Gibbs JSR, et al. Diagnosis of pulmonary hypertension. Eur Respir J 2019;53:1801904.

144. Berthelot E, Montani D, Algalarrondo V, et al. A Clinical and Echocardiographic Score to Identify Pulmonary Hypertension Due to HFpEF. J Card Fail 2017;23:29-35.

145. Forfia PR, Fisher MR, Mathai SC, et al. Tricuspid annular displacement predicts survival in pulmonary hypertension. Am J Respir Crit Care Med 2006;174:1034-41.

146. Mathai SC, Sibley CT, Forfia PR, et al. Tricuspid annular plane systolic excursion is a robust outcome measure in systemic sclerosis-associated pulmonary arterial hypertension. J Rheumatol 2011;38:2410-8.

147. Ryo K, Goda A, Onishi T, et al. Characterization of right ventricular remodeling in pulmonary hypertension associated with patient outcomes by 3 -dimensional wall motion tracking echocardiography. Circ Cardiovasc Imaging 2015;8:e003176.

148. Swift AJ, Capener D, Johns C, et al. Magnetic Resonance Imaging in the Prognostic Evaluation of Patients with Pulmonary Arterial Hypertension. Am J Respir Crit Care Med 2017;196:228-39.

149. Sanders J, Koestenberger M, Rosenkranz S, et al. Right ventricular dysfunction and long-term risk of death. Cardiovasc Diagn Ther 2020;10:1646-58.

150. Burke MA, Katz DH, Beussink L, et al. Prognostic importance of pathophysiologic markers in patients with heart failure and preserved ejection fraction. Circ Heart Fail 2014;7:288-99.

151. Hussain I, Mohammed SF, Forfia PR, et al. Impaired Right Ventricular-Pulmonary Arterial Coupling and Effect of Sildenafil in Heart Failure With Preserved Ejection Fraction: An Ancillary Analysis From the Phosphodiesterase-5 Inhibition to Improve Clinical Status And Exercise Capacity in Diastolic Heart Failure (RELAX) Trial. Circ Heart Fail 2016;9:e002729.

152. Morris DA, Krisper M, Nakatani S, et al. Normal range 
and usefulness of right ventricular systolic strain to detect subtle right ventricular systolic abnormalities in patients with heart failure: a multicentre study. Eur Heart J Cardiovasc Imaging 2017;18:212-23.

153. Hsu S, Simpson CE, Houston BA, et al. Multi-beat right ventricular-arterial coupling predicts clinical worsening in pulmonary arterial hypertension. J Am Heart Assoc 2020;9:e016031.

154. Brewis MJ, Bellofiore A, Vanderpool RR, et al. Imaging right ventricular function to predict outcome in pulmonary arterial hypertension. Int J Cardiol 2016;218:206-11.

155. Tang BT, Pickard SS, Chan FP, et al. Wall shear stress is decreased in the pulmonary arteries of patients with pulmonary arterial hypertension: An imagebased, computational fluid dynamics study. Pulm Circ

Cite this article as: Bernardo RJ, Haddad F, Couture EJ, Hansmann G, de Jesus Perez VA, Denault AY, de Man FS, Amsallem M. Mechanics of right ventricular dysfunction in pulmonary arterial hypertension and heart failure with preserved ejection fraction. Cardiovasc Diagn Ther 2020;10(5):1580-1603. doi: $10.21037 /$ cdt-20-479
2012;2:470-6.

156. Yang W, Marsden AL, Ogawa MT, et al. Right ventricular stroke work correlates with outcomes in pediatric pulmonary arterial hypertension. Pulm Circ 2018;8:2045894018780534.

157. Dawes TJW, de Marvao A, Shi W, et al. Machine Learning of Three-dimensional Right Ventricular Motion Enables Outcome Prediction in Pulmonary Hypertension: A Cardiac MR Imaging Study. Radiology 2017;283:381-90.

158. Tabassian M, Sunderji I, Erdei T, et al. Diagnosis of Heart Failure With Preserved Ejection Fraction: Machine Learning of Spatiotemporal Variations in Left Ventricular Deformation. J Am Soc Echocardiogr 2018;31:1272-84.e9. 